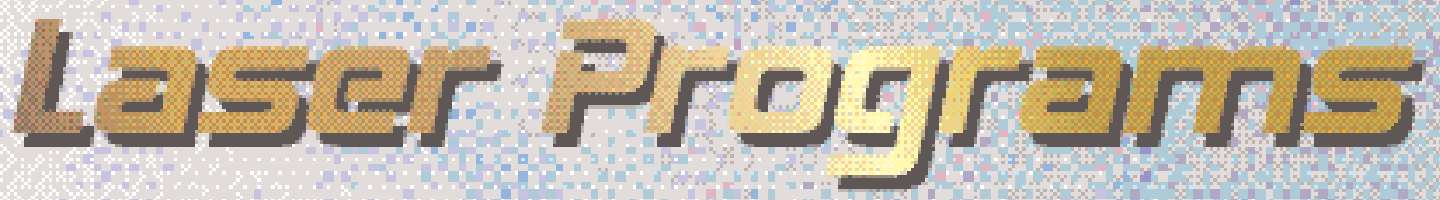

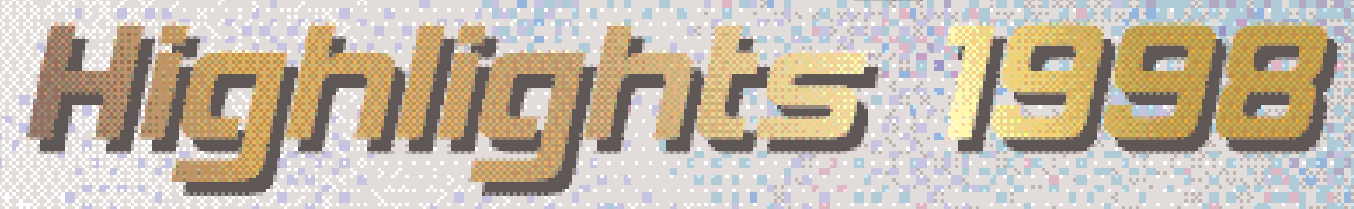

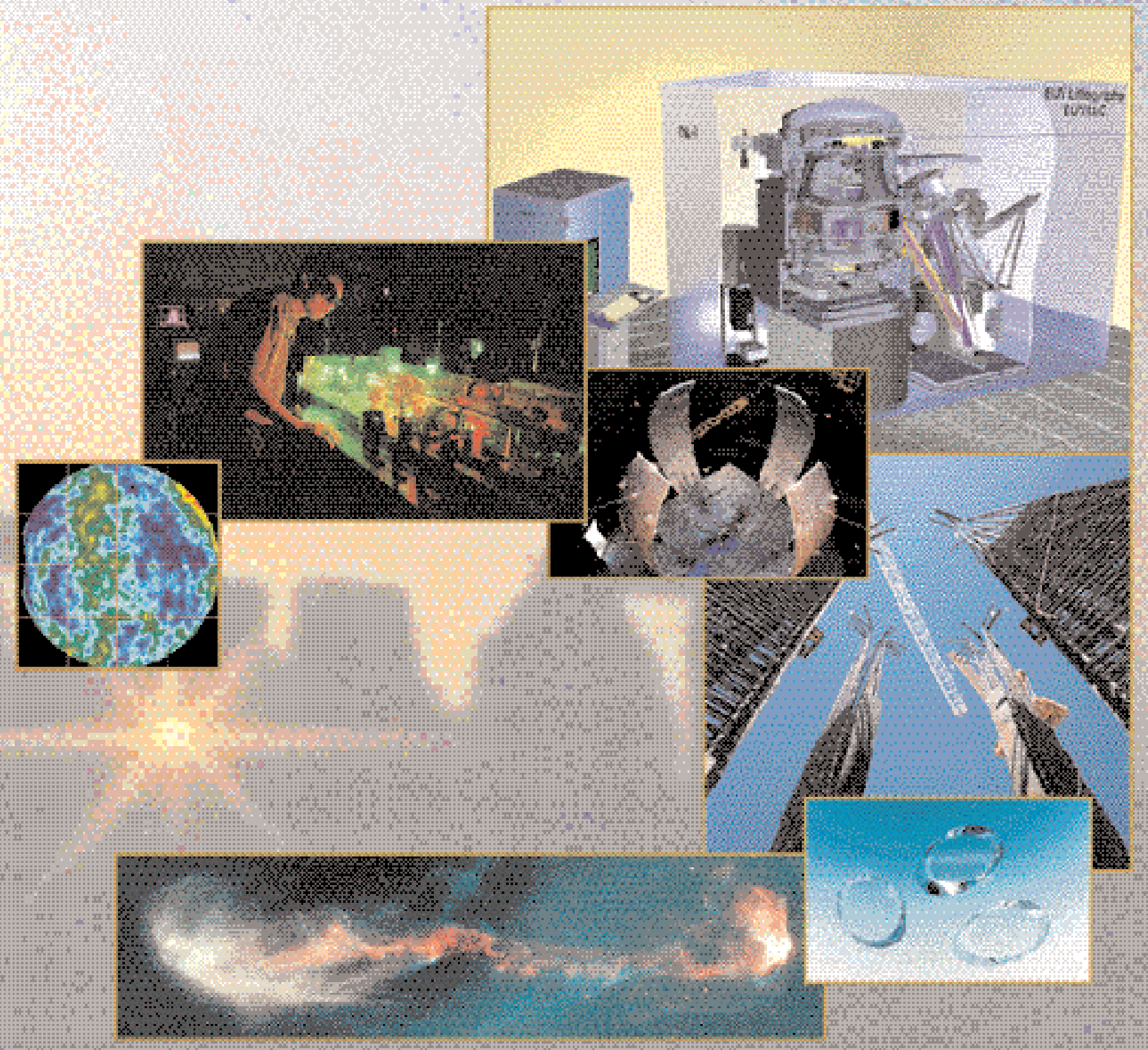




\title{
On the Front Cover
}

Clockwise from top right, schematic of the Extreme Ultraviolet Lithography (EUVL) tool designed to provide data for the development of commercial EUVL tools for etching integrated circuits; pedestal rebar that will eventually support the NIF target chamber; Yb-doped strontium fluoroapatite (Yb:S-FAP) crystal slabs being grown for the Mercury laser; an astrophysical Herbig-Haro supersonic radiation-cooled jet, which has been simulated in scientific experiments at the LLNL Nova laser; an interferometric measurement made of an assembled optical system designed for EUVL; technician checking a Ti-saphire laser regenative amplifier that is part of a high-average power chirp-pulse amplification system located at LLNL; 10-m-diameter NIF target chamber under construction with one of three tri-plates installed.

\section{On the Back Cover}

The shadows of Stonehenge, a manmade phenomenon created centuries ago, serve as the backdrop for the awe-inspiring Laser Programs accomplishments of today.

\section{Contents}

\author{
1 Commentary \\ 2 Laser Programs \\ 4 Inertial Confinement Fusion/National \\ Ignition Facility (ICF/NIF) \\ 10 Atomic Vapor Laser Isotope Separation (AVLIS) \\ 14 Laser Science and Technology (LS\&T) \\ 20 Information Science and Technology Program (IS\&T) \\ 26 Strategic Materials Applications Program (SMAP) \\ 30 Medical Technology Program (MTP)
}

34 Awards

\section{Produced by}

Technical Editor Howard Lowdermilk

Publication Editor

Cindy Cassady

Art Director/Designer

Norm Calderon-Zablocki

Art Support

Clayton Dahlen

Sandy Lynn

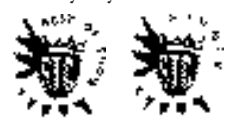

Jacquelin McBride

Proofreader

Al Miguel

\section{DISCLAIMER}

This document was prepared as an account of work sponsored by an agency of the United States Government. Neither the United States Government nor the University of California nor any of their employees, makes any warranty, express or implied, or assumes any legal liability or responsibility for the accuracy, completeness, or usefulness of any information, apparatus, product, or process disclosed, or represents that its use would not infringe privately owned rights. Reference herein to any specific commercial product, process, or service by trade name, trademark, manufacturer, or otherwise, does not necessarily constitute or imply its endorsement, recommendation, or favoring by the United States Government or the University of California. The views and opinions of authors expressed herein do not necessarily state or reflect those of the United States Government or the University of California, and shall not be used for advertising or product endorsement purposes.
This work was performed under the auspices of the U.S. Department of Energy by University of California Lawrence Livermore National Laboratory under contract No. W-7405-Eng-48. This report has been reproduced directly from the best available copy. Available to DOE and DOE contractors from the Office of Scientific and Technical Information P.O. Box 62, Oak Ridge, TN, 37831 Prices available from (615) 576-8401, FTS 626-8401

Available to the public from the National Technical Information Service U.S Department of Commerce 5285 Port Royal Rd Springfield, VA, 22161 


\section{Developing the World's Largest Precision Optical Instrument}

$\mathbf{T}$ he Laser Programs Highlights 1998 presents a summary of activities for the past year in the main programmatic areas of the Directorate: Inertial Confinement Fusion (ICF), the National Ignition Facility (NIF), Atomic Vapor Laser Isotope Separation (AVLIS), Information Science and Technology (LS\&T), the Strategic Materials Applications Program (SMAP), and the Medical Technology Program (MTP)—a joint effort with the Defense and Nuclear Technologies and the Engineering Directorates.

The Laser Programs include a diverse set of activities that range from inertial fusion to postoptical lithography for the future microelectronics industry.

Sponsorship ranges

from Department of Energy (DOE)-Defense

Programs to private industry. The connecting scientific and technological themes for these diverse programs are lasers, optics, microfabrication, high-energy-density physics, and nuclear materials. All of these activities involve multidisciplinary teams of scientists, engineers, and technical support that "push the envelope" in nationally important areas. Meeting the daunting challenges in each of these areas is made possible by the outstanding quality of the staff whose efforts continue to be reorganized by their peer community. The section on awards summarizes our 1998 accomplishments.

Another key feature of the Laser Programs is partnerships-both within the Laboratory (samples include remote sensing, nuclear materials diagnostics, medical technologies) and with other laboratories and industry (EUV lithography, inertial fusion, the NIF).

The NIF Project is being built as a major component of the DOE's Stockpile Stewardship Program to preserve confidence in the safety and reliability of remaining
U.S. nuclear weapons and to preserve core nuclear weapons competencies in the absence of nuclear testing.

The "Inertial Confinement Fusion/National Ignition Facility" article on page 4 addresses the extensive laser development program required for the NIF. Assuming ignition and gain are achieved, the NIF will be the scientific proof of principle for using inertial fusion as an energy source. Although it will require many technological developments, inertial fusion energy will not contribute to global warming, a serious world issue. Finally, the NIF will open doors for the basic sciences in the study of high-energy-density physics, the physics of the stars.

Critical partners are helping us accomplish this undertaking. France has been important in developing laser and optics technology

for the NIF and for its own planned counterpart, the Laser MegaJoule, a part of its stewardship program. We have also had valuable contributions from Sandia National Laboratories in pulsed-power technology and from the University of Rochester and Los Alamos National Laboratory in optics technology.

These developments create new opportunities for the Laboratory and for the companies with which we are working. An example of a spin-off from inertial confinement fusion is our Extreme Ultraviolet Lithography Program (see the "Information Science and Technology" article beginning on p. 20), which grew out of our target physics diagnostic work and now promises to change the way semiconductor circuits are made. Such activities keep the Laboratory squarely in the worldwide leadership role in laser technology as we approach the next millennium. 


\section{Laser Programs}

Lawrence Livermore National Laboratory's (LLNL's) Laser Programs Directorate is a world leader in laser and electro-optic science, engineering, and technology. We are applying this expertise to meet critical needs in the diverse areas of national security, energy, the environment, and the economy. We are extending our collaborations with industry and other institutions to identify technologies that can be developed and transferred to the private sector to impact various national issues.

The scientific and technical excellence of our Laser Programs staff is widely recognized nationally and internationally. Our researchers include 48 fellows of professional research societies. Over the years, Laser Programs personnel have received two Maxwell awards, eleven Excellence in Plasma Physics awards, six E. O. Lawrence awards, six Edward Teller awards, and 39 R\&D 100 awards, among others. Livermore's contributions to laser technology and it applications range from new visions in industry, energy, and defense to micro-optics for improving human vision. Our skill in translating this knowledge base into outstanding technological innovation to help solve national problems is a vital characteristic and continuing goal of Laser Programs.

Our principal laser projects derive from the core intellectual and technical capabilities developed for national security and involve the full complement of Livermore's multidisciplinary expertise. We have two long-standing major programs:

- Inertial Confinement Fusion (ICF) Program. The mission of ICF is to demonstrate in the laboratory thermonuclear fusion ignition and energy gain. LLNL's ICF Program has made great advances in understanding the scientific principles of ICF. Livermore's Nova laser has been the primary experimental tool for our ICF activities. We are advancing ICF technology in support of the Stockpile Stewardship Program and as an environmentally clean source of energy. ICF research is providing improved understanding in many areas of basic science and making contributions to meet national economic challenges. The next-generation ICF laser facility, the National Ignition Facility, now under construction at Livermore, is being developed in conjunction with the Los Alamos and Sandia National Laboratories and the University of Rochester.

- Atomic Vapor Laser Isotope Separation Program (AVLIS). The mission of the AVLIS program is to provide the world's lowest-cost, uranium-enrichment method for commercial power-plant fuel. With this method, precisely tuned laser light and uranium vapor are brought together in a separator vacuum assembly. In the separator, atoms of the ${ }^{235} \mathrm{U}$ minor isotope in an atomic vapor stream of natural isotopic composition are selectively optically excited and photoionized by laser light. The selectively ionized ${ }^{235} \mathrm{U}$ isotope is then collected to generate a product enriched in this isotope. Once enriched, the metal product is processed into nuclear fuel for power plants.

In addition, we have very successful programs in the areas described below.

The Laser Science and Technology (LS\&T) Program's current principal activities are threefold: to complete the laser technology development and laser component testing for the ICF/NIF Program, to develop advanced solid-state laser systems and optical components for the Department of Defense (DOD) and DOE, and to address the needs of other government agencies and U.S. industry. LS\&T continues to use the Beamlet laser, a fullaperture prototype of one NIF beamline, which serves as an invaluable tool for learning more about large multipass lasers. The Petawatt laser's ultrashort $(<1$ picosec) pulse, high-energy output is used to study the fast-ignitor approach for ICF. The LS\&T Program developed a critical laser driver for high-average-power applications in an inertial fusion energy plant and continues to advance diode-laser and diode-pumped laser technology for the NIF, advanced ICF systems, and a wide range of commercial and security lasers. Progress is also being made in developing high-average-power femtosecond and nanosecond lasers for materials processing and femtosecond lasers for the generation of advanced light sources.

The Information Science and Technology (IS\&T) has major efforts in developing extreme ultra-violet lithography for the fabrication of microelectronic circuits, increased magnetic disk storage capability, flat-panel display technology, adaptive optics to improve astronomical imaging, microwave sensors for precision ranging and motion detection, and photonics for high-speed instrumentation. IS\&T also houses the Imaging and Detection subprogram, which explores defense and civilian applications in signal and image processing, detection theory, radar systems, remote sensing technologies, micropower impulse radar, and airborne platforms.

The Strategic Materials Applications Program (SMAP) was created in early 1996 to consolidate a number of existing projects within LLNL's Laser Programs. SMAP develops new initiatives in the area of strategic nuclear materials and is currently engaged in developing technologies for the processing, manufacture, storage, and disposal of strategic nuclear materials (principally uranium and plutonium) associated with the nation's 
nuclear weapons stockpile. SMAP is also developing advanced techniques for the safe and secure disposition of excess nuclear materials from the DOE's inventory.

The Medical Technology P rogram (MTP) is a collaborative effort among the Engineering, Lasers, and Defense and Nuclear Technologies directorates to conduct the primary medical device research at LLNL. The fundamental tenant behind this effort is that high technology can be managed to significantly lower costs for medical care. This R\&D activity in the national interest works closely with the private sector to translate the numerous technical advances into cost-effective and practical devices and procedures to help lower the health bill for the nation.

Besides major contributions in national security, basic science, and technology applications over the past decade, these programs have provided significant advances in optics, diagnostics and sensors, materials handling and processing, microfabrication, microelectronics, information technologies, plasma physics, and inertial fusion energy research.

Numerous derivative applications of our scientific base and expanding technologies are being assessed and pursued as potential new programs in such areas as micropower impulse radar, extreme ultraviolet lithography, laser tracking and adaptive optics for astronomy applications, diode-pumped solid-state lasers, short-pulse high-irradiance lasers, remote materials handling, medical lasers, laser and radar remote sensing, $\mathrm{x}$-ray lasers, and tactical battlefield weapons.

\section{Highlights for 1998}

\section{Inertial Confinement Fusion/National Ignition Facility (ICF/NIF)}

- External review of a detailed plan to reach ignition on the NIF carried out. Work in four areas identified-hohlraum energetics, hohlraum symmetry, capsule optimization, and ignition target design and development.

- Over 950 Nova experiments performed, addressing high-energy-density physics, Defense Programs activities, and university-submitted proposals.

- Beamlet laser decommissioned and many parts sent to SNL. The space will be used for NIF amplifier frame assembly and ICF Optics Processing Development Laboratory.

- NIF conventional facilities about $40 \%$ complete, OAB made ready for final finishing, early stages of NIF Special Equipment procurement begun, and rough assembly of NIF target chamber nearly completed.

- Ability to cast laser glass for NIF was demonstrated by two vendors, and NIF-sized KDP crystals were grown by LLNL an order of magnitude faster than conditional methods.

\section{Atomic Vapor Laser Isotope Separation (AVLIS)}

- USEC AVLIS team continued plant-scale enrichment equipment verification testing and preliminary engineering for plant design and Nuclear Regulatory Commission (NRC) licensing.

- Diode-pumped solid-state lasers were demonstrated to have superior performance as pump lasers for energizing dye lasers and are now incorporated into the plant design.

\section{Laser Science and Technology (LS\&T)}

- Laser technology development and detailed Title II engineering design completed for the NIF on schedule. Overall laser performance tests completed at full scale in the Beamlet facility.

- Construction begun on a diode-pumped solid-state laser facility (Mercury), the first of a new-generation of laser drivers for high-energy-density physics and ICF.

- A fully automated femtosecond laser system for precision cutting developed and delivered to DOE's Y-12 Plant in Oak Ridge Tennessee for the Stockpile Life Extension Program.

- A flashlamp-pumped Nd:glass zig-zag laser developed and delivered to the Air Force's Advanced Imaging Testbed (AIT) project for use as a satellite illuminator.

- Laser operation successfully demonstrated in the heat capacity mode using a three-slab head as a first step toward developing a 100-kW-class mobile diode-pumped solid-state laser system for point defense against tactical missiles.

Information Science and Technology (IS\&T)

- EUVL selected by SEMATECH as the most promising of four proposed new lithography technologies for the next decade.

- Optical coatings developed that reflect EUV light close to the theoretical limit of efficiency and more uniform than ever before.

- A prototype imaging camera assembled that produced circuit features as small as $50 \mathrm{~nm}$ for use in producing defect-free masks for EUVL.

- Photonic materials development focused on the unique optical and electrical properties of nanoscale materials for use in flat-panel displays, high-speed instrumentation, and ultra-high-speed logic functions.

- Patterned array development using interference lithography successful in producing noise-free media for magnetic storage.

- Polysilicon thin-film transistors fabricated on thin, flexible, and rugged polyester plastic for use in DoD applications and low-cost consumer products.

\section{Strategic Materials Applications Program (SMAP)}

- LLNL continued as lead laboratory to develop the technology to immobilize, or chemically "lock up," excess plutonium in specially designed ceramic pellets.

- SMAP continued its program with LANL to develop a modular system to recover plutonium from excess nuclear weapons, using the prototype to help decommission the Rocky Flats plutonium pit plant

Medical Technology Program (MTP)

- Noninvasive high-resolution optical imaging systems developed for dental and other medical applications.

- A 3-year Ultrasonic Mammography Program begun to develop a new paradigm for breast cancer screening.

- Minimally invasive endovascular photoacoustic recanalization developed that couples laser light with an optical fiber to successfully disrupt blood clots and reestablish blood flow to the brain.

- Light-activated microgripper used to treat aneurysms in the brain.

- Fluorescence-based sensor developed to monitor glucose levels for treating diabetes. 


\section{Ignition Physics}

The LLNL ICF Program has worked with the ICF programs at Los Alamos National Laboratory (LANL) and Sandia National Laboratories (SNL) to develop a National Ignition Plan for attaining ignition by indirect drive on the NIF. This plan, begun the previous year, has identified work in four research areas-hohlraum energetics, hohlraum symmetry, capsule optimization, and ignition target design and development. This plan underwent external review in December. The external reviewers found that the plan is "comprehensive" and that "it carried forward all important issues that we know of at this time that will need to be resolved for ignition to be achieved." Presently, similar plans are being developed for direct-drive ignition on the NIF and for the other SSP missions.

Experiments on Nova continued last year on ignition physics in support of the indirect-drive ignition plan. In the area of hohlraum energetics, x-ray flux from laserheated hohlraum experiments, with a variety of target and laser irradiation conditions performed in collaboration with the Commissariat à L'Énergie Atomique (CEA), has been predicted by the two-dimensional radiation hydrodynamics code, LASNEX, to an accuracy of $\pm 10 \%$. In other experiments done in collaboration with CEA, low scattering levels were observed from plasmas approximating NIF conditions, irradiated with beams approximating NIF beams in their focal properties and with beam condi- tioning using smoothing by spectral dispersion (SSD). Additional experiments, also in collaboration with CEA, show that another beam-smoothing scheme, polarization smoothing, is also effective at reducing beam scattering levels. By combining both polarization and SSD smoothing, scattering levels are further reduced. These results are in qualitative agreement with simulations of beam propagation through NIF plasmas.

During the last year these calculations, using the ray tracing code $\mathrm{pF} 3 \mathrm{D}$, have been transferred to the massively parallel machines being developed by the Accelerated Strategic Computing Initiative (ASCI) Program. This enhanced computational capability allows the calculation of a full NIF beam along the entire path of a NIF target. These results provide enhanced confidence that adequate $\mathrm{x}$-ray drive can be achieved on the NIF to obtain ignition.

Experiments on hohlraum symmetry were performed using the OMEGA laser at the University of Rochester Laboratory for Laser Energetics (LLE). The OMEGA laser has comparable energy to Nova but with up to four times as many beams entering into a cylindrical hohlraum target. Initial experiments performed last year showed that improved implosions could be obtained on OMEGA using forty beams compared to Nova's ten beams. Preliminary analysis shows that mix studies may be accomplished with small effects due to drive asymmetry.

During this past year Nova experiments began exploring characteristics of different potential capsule materials. Initial ignition
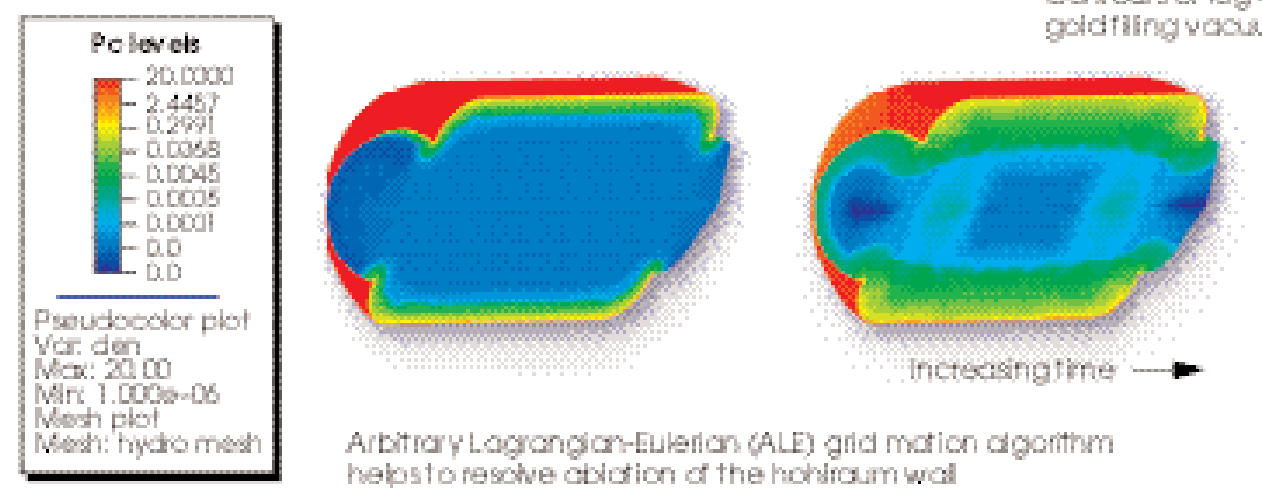

Arbitray Lograngan-Eulerian (ALE) grid mation dgorithm hebs to resche ctidion of the hotioum wal

Three-dimensional modeling capability simulating the radiation hydrodynamics of hohlraums. The three figures show the hohlraum density at three times for a NIF-size hohlraum. 
The cooling and heating mechanisms envisaged for forming smooth symmetric cryogenic layers in the ICF capsule in the conceptual design of a NIF cryogenic target.

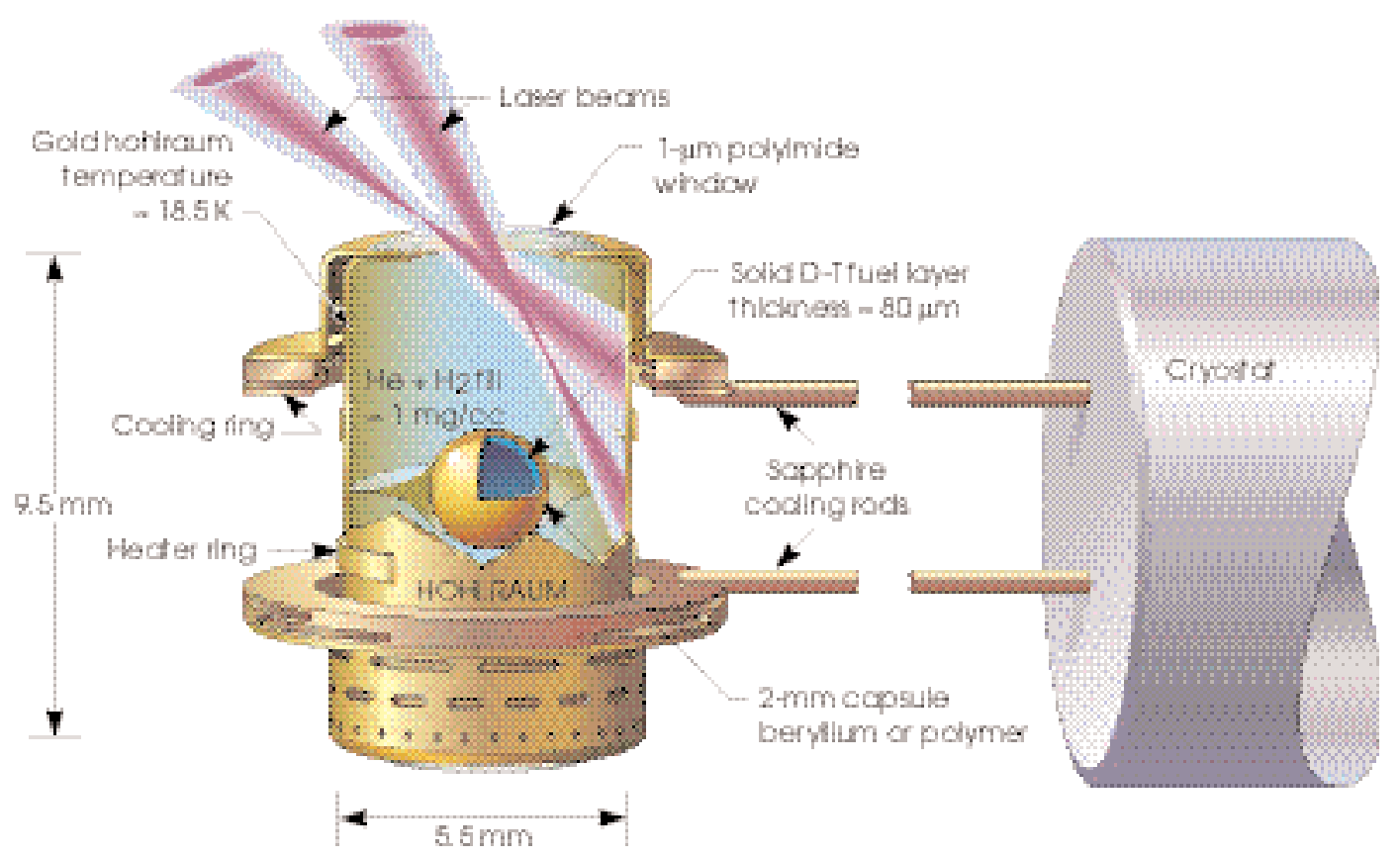

designs were developed for capsules whose shell is made of plastic $(\mathrm{CH})$ doped with higher $\mathrm{Z}$ materials, and an extensive database was developed studying the shell's response to $\mathrm{x}$ rays and its susceptibility to hydrodynamic instabilities. More recent ignition designs have been developed using doped beryllium and polyimide capsules. During the past year experiments were conducted to study these materials.

Progress continues to be made in ignition target design to broaden the suite of capsule designs for ignition. During the last year, ignition capsule designs continued to be developed for polyimide and doped beryllium ablators. In addition, design work continued pushing the design envelope to higher-drive temperatures using smaller holhraums. The three-dimensional code, HYDRA, continued to be developed. The first hohlraum calculations were completed with radiation sources, using the massively parallel ASCI computers.

\section{Target and Diagnostic Technology}

Target development focused on technologies for fabricating NIF ignition targets. Progress continued in developing capsules with either a beryllium or a polyimide ablator. In collaboration with the Chemistry Directorate, a technique was developed to sputter deposit smooth beryllium films by adding boron, and a new vapor deposition process for coating polyimide on spherical mandrels was demonstrated. The technique for producing smooth cryogenic layers of deuterium and tritium inside a capsule was shown to produce reproducible layers of desired uniformity and smoothness. A cryogenic system was completed last year to begin the study of producing uniform layers in capsules inside hohlraum targets.

In diagnostic development, a charged particle spectrometer was installed on the OMEGA laser in collaboration with the University of Rochester and the Massachusetts Institute of Technology to measure charged particles produced from an implosion. Charged particle spectra can potentially provide understanding of the implosion process. A prototype of a new $\mathrm{x}$-ray streak camera was shown to have better spatial resolution than present x-ray streak cameras. In the new cameras, the signal is directly recorded on a charge-coupled device (CCD) detector instead of using an optical phosphor screen that is coupled by a microchannel plate intensifier to film or CCD.

\section{High-Energy-Density Physics}

During the past year, experiments on Nova addressed several problems in HED physics. The generation and propagation of 
supersonic jets ( Mach 8 ) were studied into the nonlinear regime in collaboration with LANL and the Atomic Weapons Establishment (AWE) of the United Kingdom. In other experiments, the dispersion curve for the hydrodynamic growth rate of the Rayleigh-Taylor instability was measured, and the short wavelength cutoff of instability growth due to ablative stabilization was observed conclusively for the first time in steady-state acceleration. A new radiation drive source was developed using half of the Nova beams in a half-hohlraum geometry. In the first experiments using this geometry, two half-hohlraums were used to generate two counterpropagating, radiationgenerated shock waves in perturbed material. A new pressure source of driving hydrodynamic experiments was developed by using supersonically heated foam to create a combination of material and ablative pressure. Equation-of-state (EOS) experiments were extended from deuterium to the diamond form of carbon. In these new experiments in multielectron systems, the transition has been observed in strongly shocked systems from diamond as an insulator to a metal. In recognition of the experiments' importance, the American Physical Society Division of Plasma Physics gave its Award of Excellence to the scientists who performed the deuterium EOS experiments. In collaboration with the University of Maryland, the radiative collapse of supersonic jets was observed in Nova experiments. These experiments are designed to study radiative jets in the laboratory analogous to those observed in astrophysical events. In experiments on the OMEGA laser at LLE, several HED experiments were successfully reproduced including those requiring $\mathrm{x}$-ray backlighters and classified operation. These experiments confirm that the OMEGA laser is suitable for performing HED experiments.

\section{Science Use}

An active program continued on Nova for university use. Experiments were performed on eight proposals that were selected out of twenty submitted in a peer review process. These eight proposals included researchers from sixteen universities. They covered topics in the areas of astrophysics, hydrodynamics, material properties, and atomic physics.
Approximately 8\% of Nova experiments were directed toward this effort in 1998.

\section{High-Intensity Laser-Matter Interactions}

In 1998, the Petawatt beamline of the Nova laser was upgraded by adding a deformable mirror to reduce the focal spot of the beam. Using the deformable mirror, experiments can be done with peak intensities of $3 \times$ $10^{20} \mathrm{~W} / \mathrm{cm}^{2}$. During the last year, experiments showed that high-energy electrons with mean energy of $\sim 7 \mathrm{MeV}$ could be produced and that the angular distribution peaks in the forward direction. These experiments were performed in collaboration with the Defense and Nuclear Technologies and the Physics and Space Technology Directorates. These electrons can deposit their energy in dense matter producing high-energy $\mathrm{x}$ rays that have been shown to be a potential source for radiography applications. It was discovered that the hard $\mathrm{x}$ rays were sufficiently energetic to induce nuclear reactions that could subsequently be used as a diagnostic technique. It was also shown that the electrons could heat the dense matter to temperatures sufficient for producing thermal nuclear reactions in deuterium plasmas.

\section{Facility Operations and NIF Transition}

In 1998, Nova continued to be a productive research facility. It performed over 950 experiments and exceeded the planned level of shots. Eighty percent of the shots were done in support of Defense Programs activities in collaboration with $\mathrm{A}$ and $\mathrm{B}$ Programs at LLNL as well as with CEA and AWE on some experiments. Approximately $8 \%$ of the experiments (8) were done in support of University Use of Nova by teams of university scientists.

The Beamlet laser completed its mission in support of the NIF design and was decommissioned. The laser was removed from the building, and many of its parts sent to SNL where it will be rebuilt as a backlighter source for the Z-pulse power facility. The space is being renovated for reuse, initially by the NIF Project for amplifier frame assembly. The 2-Beam area of Nova is also being converted to the ICF Optics Processing Development Laboratory. This laboratory will contain a 5500-sq-ft clean room for 
developing, cleaning, and coating processes of large-scale and NIF optics. An additional $3000 \mathrm{sq} \mathrm{ft}$ of clean room space in this facility will come on line in 1999.

\section{The National Ignition Facility Project}

Upon completion, NIF will be the largest and most complex laser-target interaction system ever constructed. It is a key component of the DOE science-based SSP and will allow researchers to study the physics of matter interactions and fusion ignition under conditions of extreme temperature and pressure similar to those found in nuclear weapons and astrophysical objects. The driver is a 192-beam Nd-glass laser capable of irradiating millimeter-sized targets with power up to 500 terawatts $\left(5 \times 10^{12} \mathrm{~W}\right)$ in pulses of a few nanoseconds $\left(10^{-9} \mathrm{~s}\right)$.

At the beginning of 1998, excavations for the NIF foundations were complete, and building construction had begun. By the end of 1998, the NIF conventional facilities (buildings, utilities, etc.) were about $40 \%$ complete. The optics assembly building was ready for final finishing, and the installation of support pedestals for the optics handling equipment had begun. The laser building was closed in, and construction of the concrete walls of the target area and switchyard structure had begun. Construction remains generally on schedule, with minor perturbations that are unlikely to affect planned completion in late FY01.

\section{NIF Special Equipment}

The NIF Special Equipment (laser and target chamber equipment) proceeded through Title II (final) design and the early stages of procurement in 1998. Title II design will be largely complete by July 1999 .

The first major piece of special equipment to be installed will be the 10-m-diam aluminum target chamber. Rough assembly of the chamber was completed in January 1999. Laser and diagnostics ports are being machined in the chamber, and it will be lifted onto its pedestal in the partially completed target area building in June 1999.

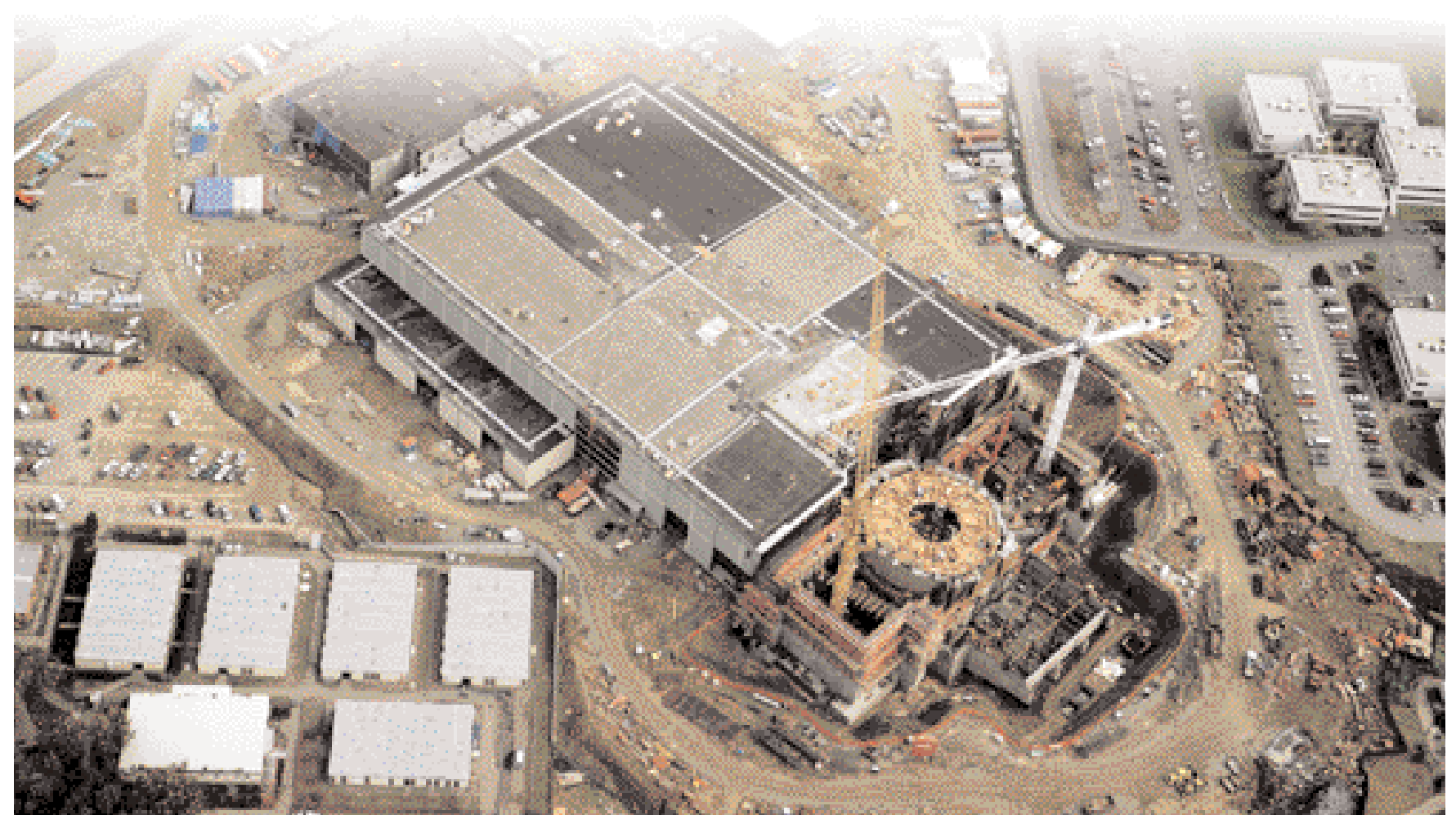

The site of the NIF on January 21, 1999. The building covers an area of about $122 \times 166 \mathrm{~m}^{2}$. The large flat-roofed area in the center is the laser building, and the round structure to the right is the cylindrical target area building. At the upper left is the optics assembly building. 
Contracts have been let for the large stainless-steel spatial filter vacuum vessels and beam tubes for the NIF, and construction is well under way at several vendors. Early production beam tubes will soon be delivered. Contracts have also been let for the amplifier and support structure, and some of these parts have been delivered. One switchyard structure is under contract, and contracts are about to be let for the amplifier frames and the second switchyard structure.

First-article and prototype tests of NIF laser hardware are proceeding well. The first-article power conditioning module for the amplifier pulsed power system was completed and tested successfully at SNL. Tests using actual NIF flashlamps will commence early in 1999.

Mechanical components for the first-article Pockels cell assembly are being ordered, following successful tests of separate mechanical and electro-optical prototype assemblies. Tests of the prototype amplifier assembly were completed successfully in the Amplifier Module Prototype Laboratory, and first-article hardware is on order.

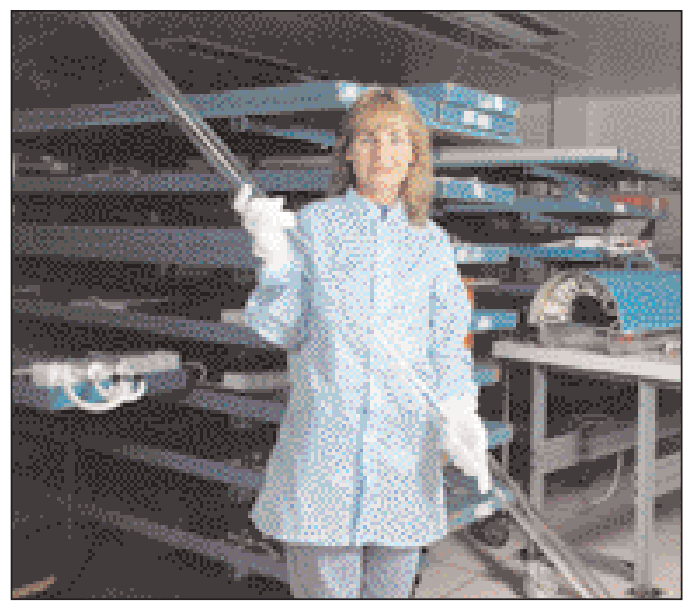

Technician holding a NIF flashlamp, which is about the size of an 8-ft fluorescent lamp bulb.

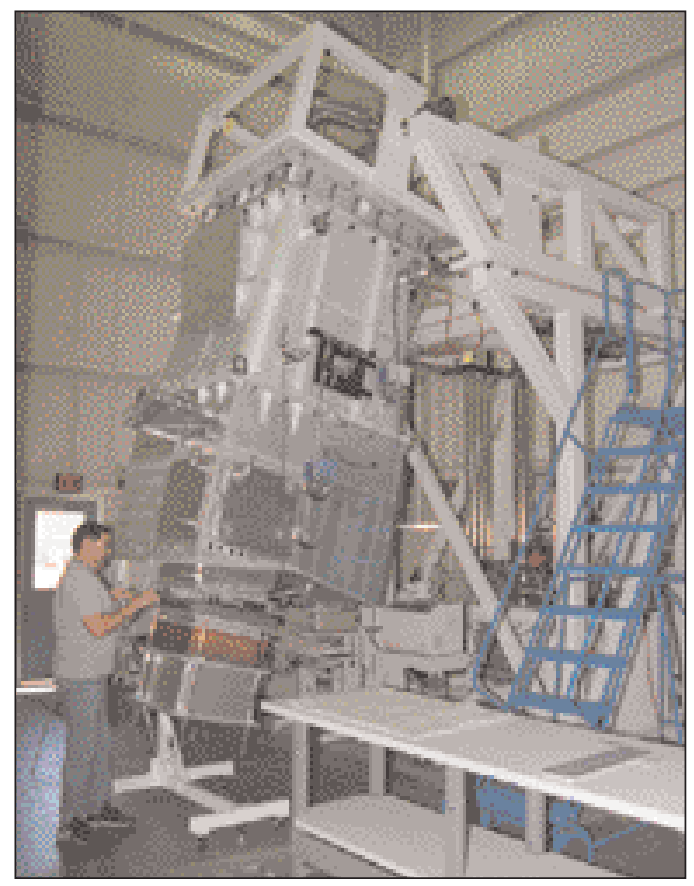

A prototype for a NIF optics transporter (above) inserts a vertical linereplaceable unit (LRU) stack of four amplifier slabs into an overhead frame. In the actual NIF facility, the entire ceiling of the amplifier area will be covered with close-packed frames waiting to receive LRUs.

\section{NIF Optics}

The NIF will contain more than 7000 large optical components to be delivered over a period of about four years. This level of production requires new NIF-funded facilities in industry, and these facilities were largely completed in 1998. Major optical fabricators have delivered early pilot production samples of spatial filter lenses and laser slabs, and pilot studies on other components are beginning. Two vendors have demonstrated that they can fabricate polarizers that meet NIF requirements.

About half the NIF optics are neodymium-doped phosphate glass laser slabs. Two vendors demonstrated the ability to cast laser glass in NIF sizes and close to NIF specifications during 1998 in a pilot program jointly funded by the NIF project and the CEA.

\section{KDP Crystals}

The NIF will contain almost 600 large plates of KDP or DKDP (normal or deuterated potassium dihydrogen phosphate) crystal with a clear aperture of $40 \mathrm{~cm}$. Research at LLNL has demonstrated techniques for growing these crystals at a rate about an order of magnitude faster than that of well-developed conventional growth techniques. This technology is now being transferred to commercial vendors. A new NIF-funded

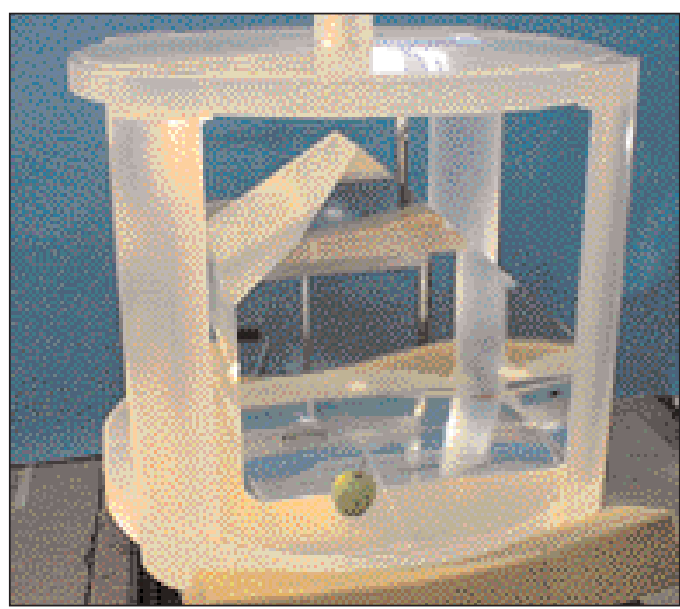
high-precision diamond lathe was delivered in 1998 that will be installed at a finishing vendor to finish these plates.
An early rapid-growth pilot production boule of KDP for NIF doublers. It measures about $54 \times 57 \times 56 \mathrm{~cm}^{3}$ and weighs $278 \mathrm{~kg}$. 


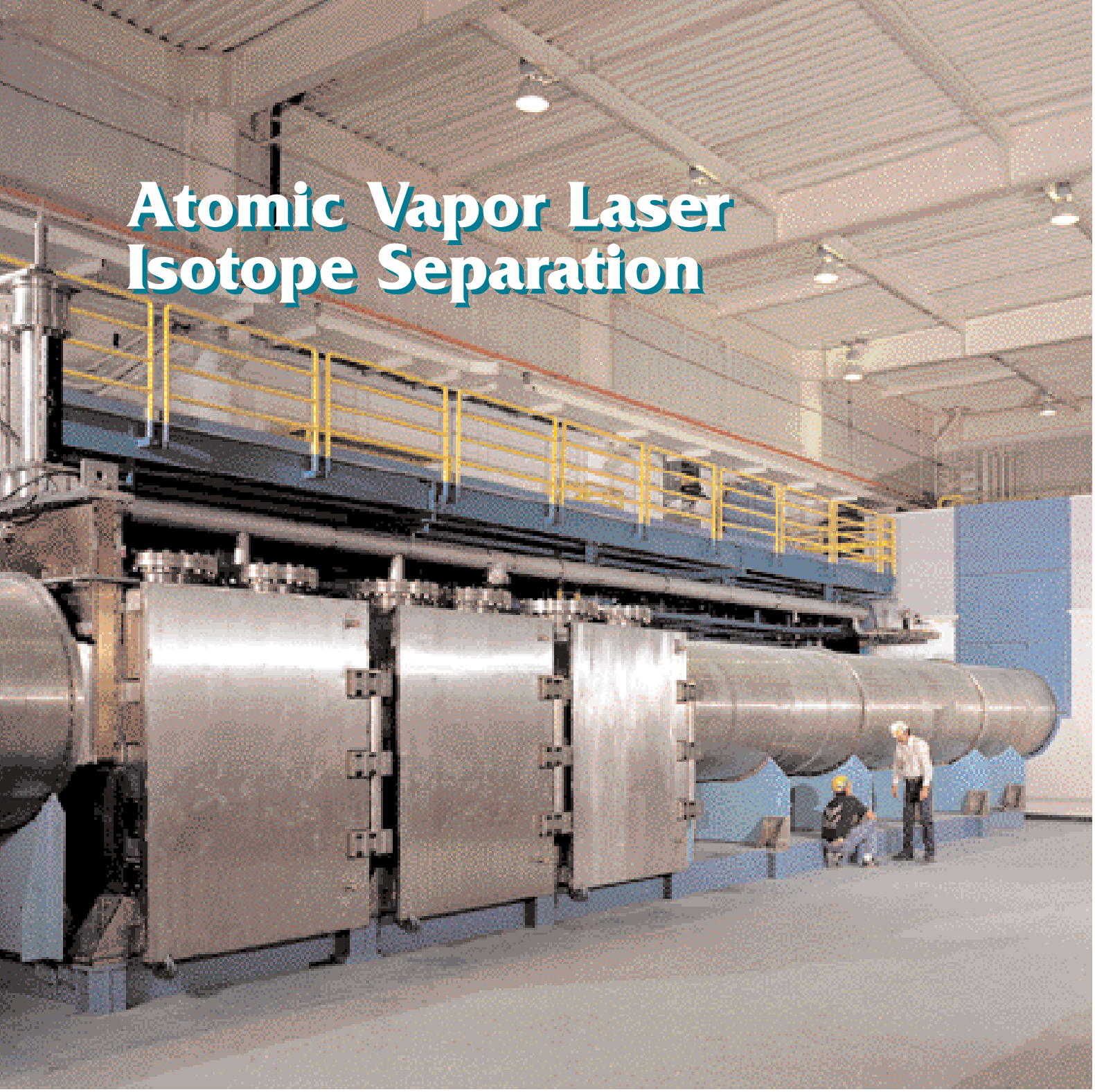

Plant-scale uranium separator system

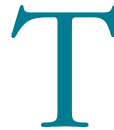

he Atomic Vapor Laser Isotope Separation (AVLIS) Program's mission is to provide the world's lowest-cost enriched uranium for commercial power-plant fuel. The major building blocks of the AVLIS process include separators, lasers, and optical systems.

The separation process uses finely tuned, high-power lasers to tag the fissile isotope of uranium by removing one of its electrons. The product stream is formed by collecting the resulting ${ }^{235} \mathrm{U}$ ions on charged plates. This process takes place in a vacuum chamber where the uranium is vaporized and exposed to the laser beams. The product is removed as small nuggets of solid uranium metal that, with further chemical processing and fabrication, yield finished fuel for use in nuclear power reactors. 
The AVLIS Program is funded by the United States Enrichment Corporation (USEC), formerly a government corporation before privatization in July 1998 in the fifth largest initial public offering on the New York Stock Exchange. USEC supplies enrichment services to the nuclear fuel industry using existing gaseous diffusion plants located in Kentucky and Ohio. AVLIS offers USEC a lower-cost option for enriching uranium to meet customer demand, with plant initial production targeted for 2005.

This year, USEC's AVLIS team continued to move forward with plant-scale enrichment equipment verification testing and with preliminary engineering needed to begin plant design and Nuclear Regulatory Commission (NRC) licensing. This team includes Bechtel National Inc., Duke Engineering, On-Site Engineering, Babcock and Wilcox, Lockheed Martin, AlliedSignal Corp., LLNL, and USEC.

\section{Separator and Laser System Demonstrations}

The AVLIS enrichment process has been developed since the early 1970 s with about $\$ 2$ billion of government resources (DOE and USEC) and, for the past several months, from the privatized USEC. Since completion of USEC's pilot plant at LLNL in the fall of 1997, full-scale hardware has been tested for long duration at levels approaching plant technical requirements. Current demonstration status (March 1999) supports enrichment cost projections (including research, development, and demonstrations [RD\&D], taxes, and investment profit) comparable to current estimates for USEC's gaseous diffusion plants. This projection does not take credit for expected improvements during completion of pilot testing.

These enrichment tests are intended to address two key remaining issues: separator lifetime and enrichment efficiency. Modest progress, on top of the current status in each of these areas, would demonstrate sufficient performance to project costs that meet or beat all existing technologies. The first of these issues, separator lifetime, is a cost issue since it drives the plant operating and capital costs of the refurbishment facilities. Targeted life is 400 hours. After having achieved 400 hours in December 1997, the subsequent three demonstration runs fell significantly short of this target due largely to anomalous high corrosion rates of key

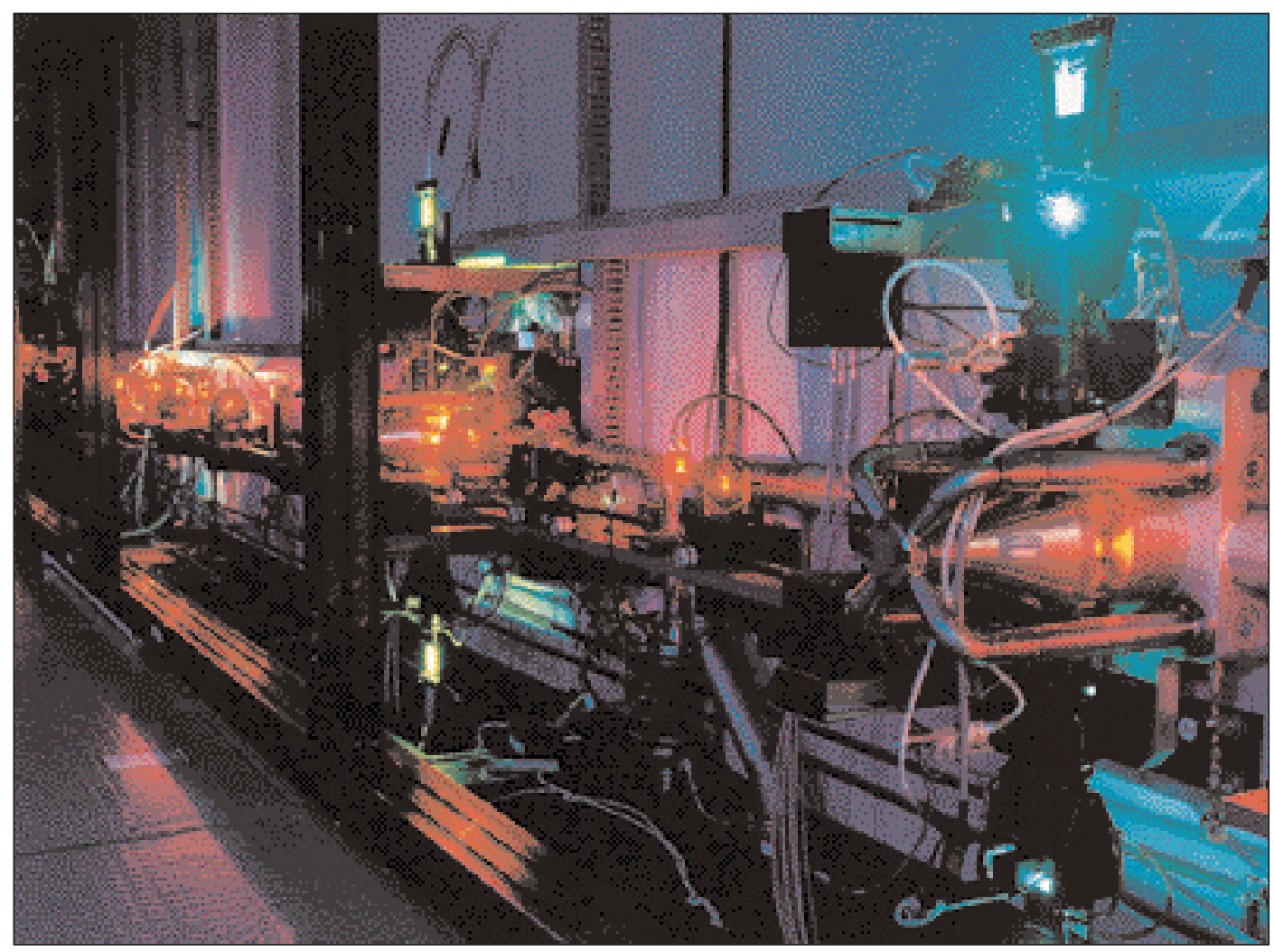

Precisely tuned, highpower AVLIS process lasers. 
separator components. The technical team, with the support of external review teams, has diagnosed the source of this behavior and verified it in a subsequent test that ran to 290 hours. This placed the project back on its long-term (3-year) trend for average life improvement and continued confidence in achieving the plant life target.

The second key issue is enrichment efficiency. This is measured by determining how well lasers produce enriched product. Current measurements show $80 \%$ of plant targeted efficiency, with the shortfall now attributed to a few laser and separator attributes such as laser beam uniformity and vapor condition. Engineering upgrades using unique deformable optics to correct beam quality are in place to address this shortfall. Separator optimization should also yield progress towards full targeted efficiency. Achievement of $80 \%$ plant enrichment levels is a significant accomplishment this past year. It was made possible by the multihundred-hour-duration separator and laser systems enrichment capability demon- strated in the March 1999 test with laser systems operating at record power levels.

In this past year, diode-pumped solidstate lasers were demonstrated to have superior performance as pump lasers for energizing dye lasers. They are now the baseline technology for the AVLIS plant and are incorporated into the plant laser facility design. These lasers are assembled from commercially available components in a rack mountable package. The solid-state infrared output (1.06 microns) is Q-switched to yield short pulses ( $85 \mathrm{~ns})$ and is frequencydoubled in second-harmonic crystals to provide green wavelengths (0.53 microns), similar to the output of copper lasers. Continuous operations in the test facility have verified component performance, lifetime, and economics. Diode-pumped units at $7 \%$ electrical efficiency (to green output) have been demonstrated at average powers exceeding 200 watts. This performance more than meets plant power pulse-length goals and results in a 35\% cost savings (relative to copper laser systems).
Rack-mounted diodepumped, solid-state lasers that provide power to dye lasers via fiber-optic cable.

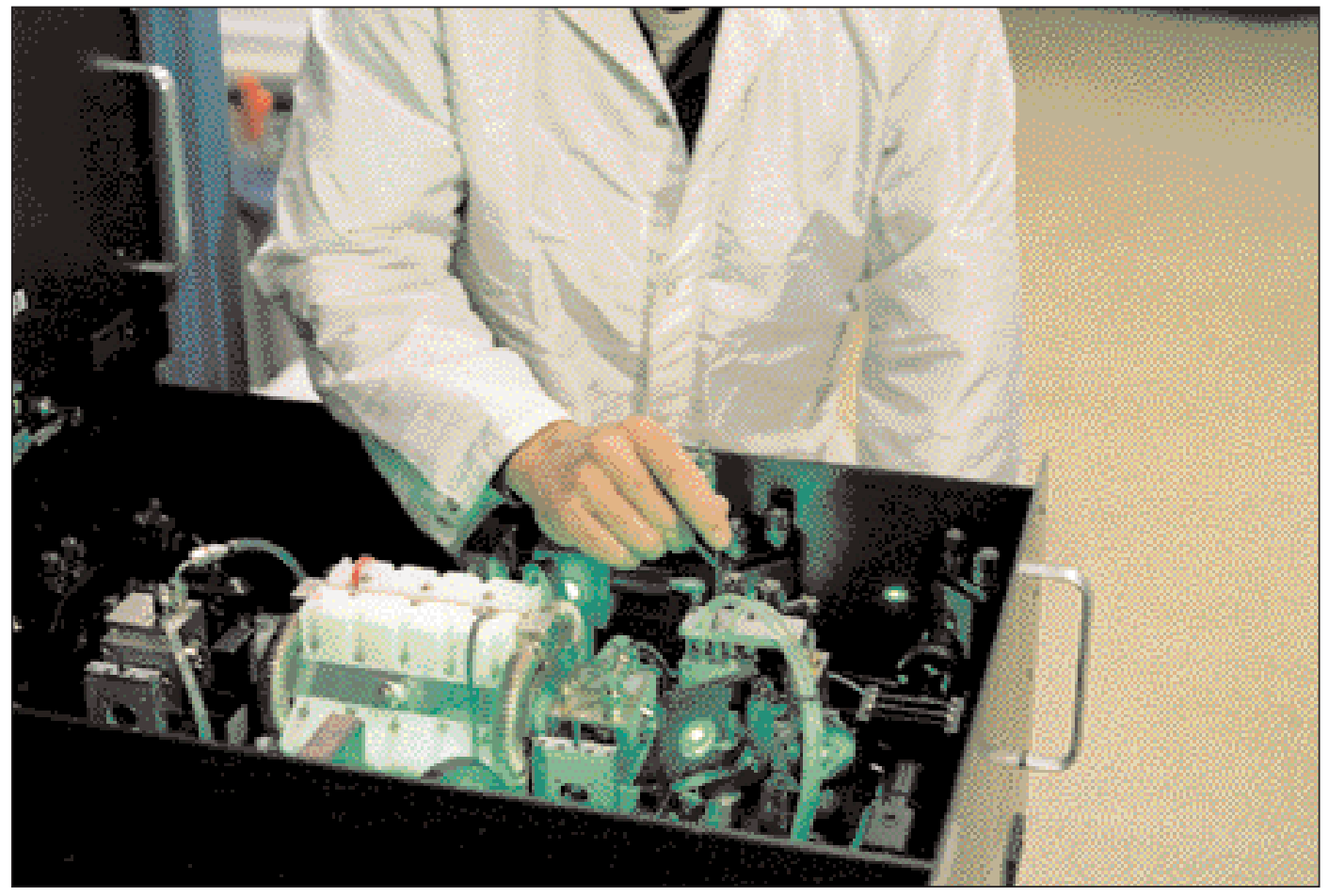




\section{Plant Design Activities}

The AVLIS Team achieved its planned 1998 objectives in the areas of plant project engineering, including 30\% completion of designs for the plant separator and laser buildings. This achievement is on schedule and is up from 10\% levels last year.

Design information is being used to develop NRC license application documentation and to support a plant construction start in 2002. The plant laser facility design was updated this year to incorporate solid-state lasers as the replacement for copper laser systems. This design change reduced plant cost and laser bay size by significant amounts.

The AVLIS Team at LLNL has verified all key scientific and technical bases for the enrichment technology. The planned completion of AVLIS full-scale equipment demonstrations in 1999 is aimed at achieving projected production costs at or below all existing means of production including the best AVLIS alternative,

European centrifuges.

Editors note: In June 1999, USEC suspended funding of the AVLIS Project and began termination of the AVLIS Team staff. During project closeout, all technical and engineering information will be documented and stored for possible future use. USEC retains exclusive rights to AVLIS technology for commercial applications, and the U.S. government retains all rights to the technology for its purposes.

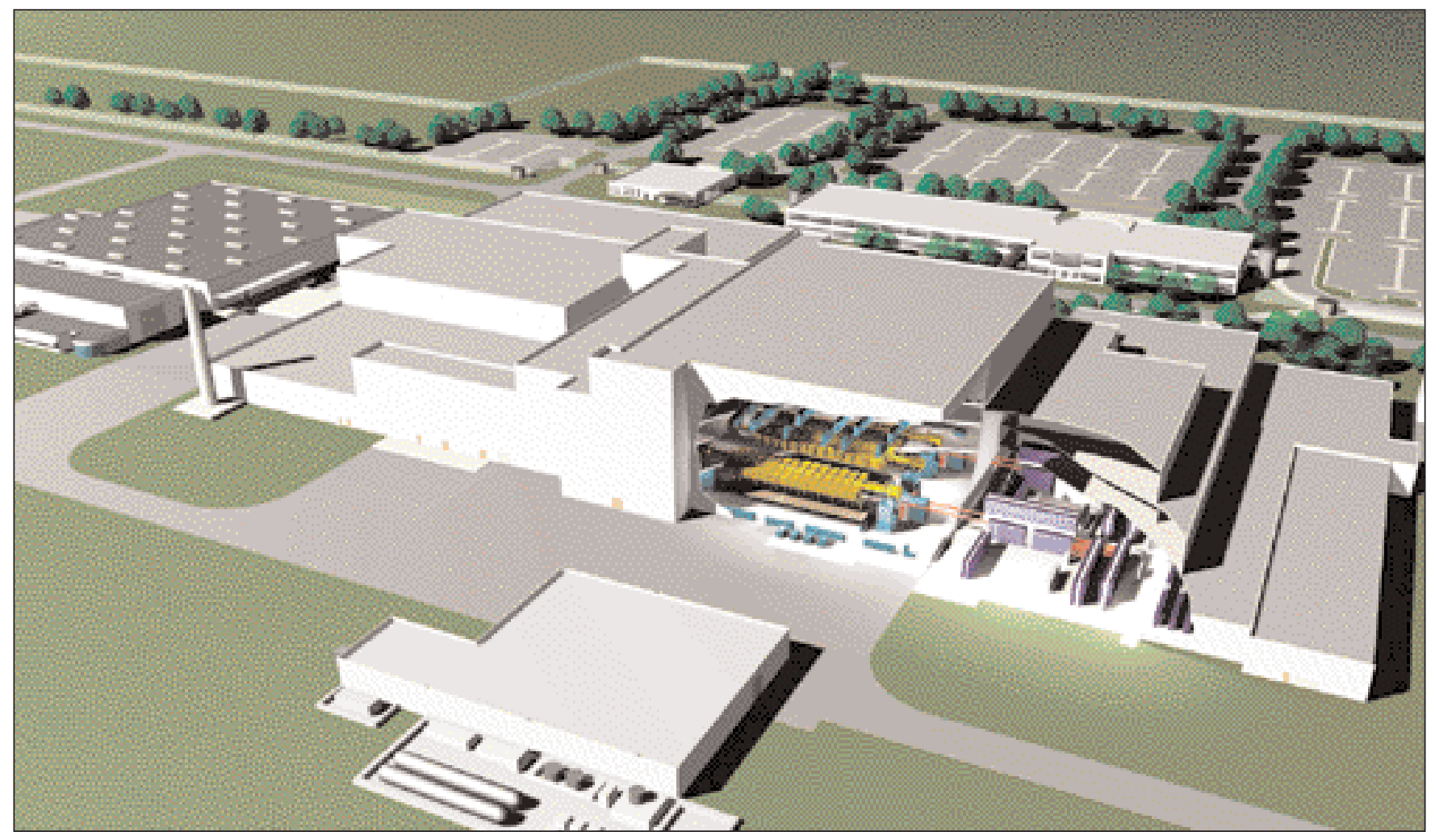

Schematic of the AVLIS plant in the 2006 timeframe, which could be able to provide the world's lowest cost fuel for commercial electric power generation. 


\section{Completion of NIF Laser Component Development}

The NIF laser technology development effort was successfully completed in 1998. All key components required for deploying the NIF's 1.8-MJ laser system were developed and tested. These components include the optical pulse generator, main amplifier, power conditioning, plasma electrode Pockels cell (PEPC), beam control, and integrated computer control systems. The overall system performance was tested at full-scale aperture in the Beamlet facility. Data collected from Beamlet were subsequently used by the engineers to validate the design and cost of the NIF laser. Timely completion of this development effort enabled the NIF Project to maintain its schedule to proceed toward the first-bundle operation and target experiment beginning in 2002

The front end of the NIF laser chains is an optical pulse generation system that consists of an optical fiber-based master oscillator, fiber amplitude and frequency modulators for pulse shaping, and a fiber amplifier network that delivers nanojoulelevel inputs to the 48 preamplifier modules. In 1998, LS\&T assembled a prototype optical pulse generation system and successfully verified its performance at NIF operating conditions.

Progress was also made in the NIF laser amplifier area. The Amplifier Module Prototype Laboratory (AMPLAB), a facility specifically constructed for testing of fullscale NIF amplifiers, was in operation in 1998. Amplifier gain, gain uniformity, prompt pump-induced wavefront distortion, and thermal recovery time of amplifier structures were systematically measured under various operating conditions. Engineering data on amplifier assembly, maintenance, and cleanliness requirements were also obtained.

Current results indicate that the residual optical distortion introduced by the preceding laser pulses can be adequately reduced within a 7-hour time frame. To develop qualified vendors for the NIF, the AMPLAB engineers worked closely with several potential vendors and validated the performance of vendor-produced flashlamps and capacitors.

A NIF-size, $4 \times 1$ PEPC was constructed and tested. Simultaneous switching of all four apertures was demonstrated with an extinction ratio (which is a measure of the fraction of laser light remaining in the undesired polarization) exceeding that required for NIF operation. A prototype power-conditioning module using a Maxwell/ PI sparkgap switch design was also assembled and tested at SNL, Albuquerque. LS\&T also completed the development and testing of a $40-\mathrm{cm}$ deformable mirror (controlled with 39 actuators) in Beamlet. The LS\&T team was able to build another $40-\mathrm{cm}$ mirror capable of reducing static and pump-induced wavefront distortion to yield an output beam near $2 \times$ diffraction-limited. Vendor development to produce large-aperture deformable mirrors for NIF is ongoing.

Development of the NIF computer control system was concentrated on the overall system architecture and supervisory software framework. In the beam control areas, a prototype power balance diagnostic system was developed. This special tool enabled the simultaneous measurement of the power of both $1 \omega$ and $3 \omega$ beams with high accuracy.

Beamlet completed its main mission as the laser physics and engineering testbed in 1998. During its entire service life, over 1000 full-system laser shots were fired, which supported over 20 experimental campaigns. LS\&T demonstrated $1 \omega$ output beam quality equivalent to that required for achieving ignition in the NIF. The performance of the final optics assembly was tested under NIF operating conditions (using lasers with fluence near $8 \mathrm{~J} / \mathrm{cm}^{2}$ at $3 \omega$ ). The final optics assembly consists of large-aperture frequency conversion crystals, a focusing lens, and a diffractive optics package. Beamlet experiments demonstrated that over $73 \%$ of the

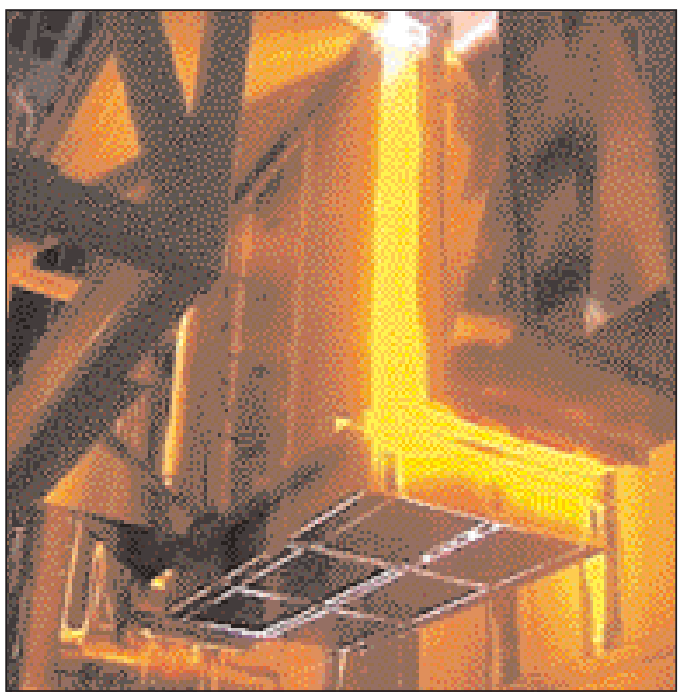

A full-scale slab amplifier being tested in the AMPLAB facility. The facility is capable of testing 4 $\times 2$ modules (four slabs high by two slabs wide, up to three slabs long) under various operating configurations. 
$1 \omega$ beam power could be efficiently converted to $3 \omega$ using rapid-growth KDP crystals. Beamlet experiments utilizing beam smoothing by spectral dispersion (SSD) clearly demonstrated that the current NIF design is adequate to control the uniformity of the focused beam on target.

Upon completing its mission, the Beamlet facility was disassembled. The majority of its components have been shipped to SNL at Albuquerque, where they will be utilized to construct a high-power laser beamlet in the $\mathrm{Z}$-accelerator facility to generate $\mathrm{x}$ rays for backlighting experiments. In 1998, LS\&T scientists completed a conceptual design for SNL's beamlet. When constructed, Z-Beamlet will have an output of $2 \mathrm{~kJ}$ at $2 \omega$ with a pulse duration of $2 \mathrm{~ns}$.

\section{Laser Modeling and Optimization}

LS\&T continues to refine the laser physics models and carry out modeling calculations to optimize the performance of the NIF laser. The majority of the NIF's optical components was examined with an ultimate goal of reducing costs and risks. Wavefront distortion introduced by the mirror fabrication and coating processes was investigated. A comprehensive wavefront correction model that can account for most of the factors

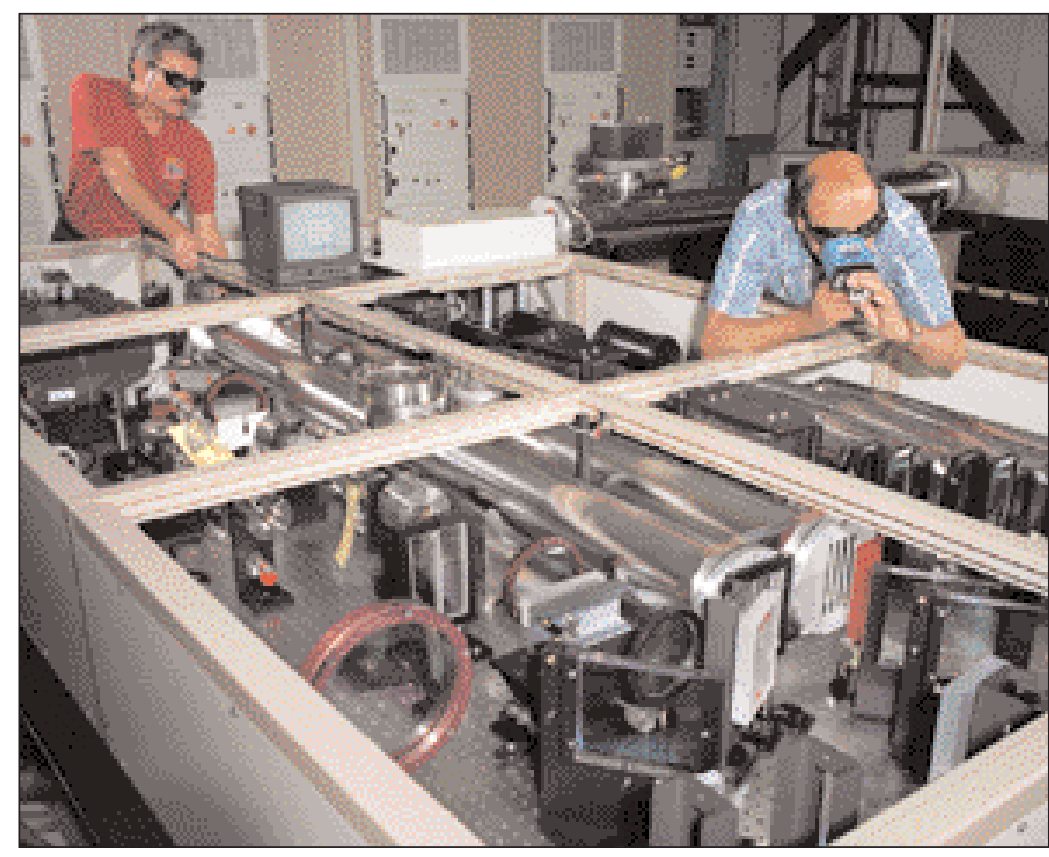

A flashlamp-pumped Nd:glass zig-zag laser (60-J, 600-ns green pulses at $3 \mathrm{~Hz}$ with $2 \times$ diffraction-limited beam quality) for the Air Force's Advanced Imaging Testbed project at the Starfire Optical Range for use as a satellite illuminator. influencing NIF beam quality was developed. Current calculation indicates that air turbulence near the main amplifier system can have a large impact on the spot size achievable in the NIF. A 3-dimensional ray trace code has also been developed to model the optical gain and gain profile in the amplifier slabs. Utilizing this code, LS\&T scientists have been able to optimize the design of NIF amplifiers with confidence and without additional experiments.

\section{High-Average-Power Solid-State Lasers for the Department of Defense}

High-power solid-state laser and largeaperture optics capabilities developed by LS\&T have many defense applications. In 1998, a flashlamp-pumped Nd:glass zig-zag laser was completed for the Air Force's Advanced Imaging Testbed (AIT) project at the Starfire Optical Range. This laser has four gain modules with four output beams that are phase-locked together in a phase-conjugating cell filled with highpressure xenon. The AIT laser was delivered to the Air Force Research Laboratory at Albuquerque in January 1998. It can deliver up to 60-J, 600-ns green pulses at $3 \mathrm{~Hz}$ with beam quality, coherence length, and pointing stability very close to the Air Force's requirements. The Air Force currently uses the AIT laser as a utility for the satellite illumination experiments. In partnership with a major aerospace company, LS\&T is also investigating a high-average-power, highbrightness Yb:YAG rod laser for military target illuminators. When completed, it will have a Q-switched output of $>400 \mathrm{~W}$ with $\mathrm{M}^{2}<3$.

LS\&T is working in partnership with Raytheon Corporation to develop a 100-kW-class solid-state laser for the High Energy Laser Strategic Test Facility (HELSTF) in New Mexico. The HELSTF laser is based on LLNL's heat-capacity operation concept. When completed, it will be pumped by high-power laser diode arrays and will be capable of delivering $100 \mathrm{~kW}$-to-MW output power (burst mode for the duration of several seconds) for point defense against tactical missiles. In 1998, using flashlamps as a surrogate pump source, LS\&T successfully demonstrated laser operation in the heat-capacity 


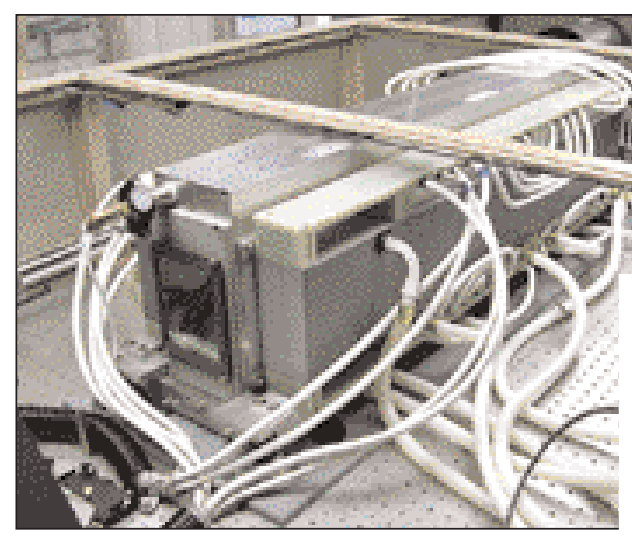

mode and obtained $1.5-\mathrm{kW}$ output for $10 \mathrm{~s}$ from a three-slab testbed. LS\&T sci entists also investigated several diode cooling and packaging techniques. A monolithic microchannel cooler, capabls of removing waste heat from the diode arrays at $1 \mathrm{~kW} / \mathrm{cm}^{2}$, was designed and tesi A 10-bar prototype monolithic diode array was operated. An adaptive resonator cavity was also developed to control the beam quality of heat-capacity lasers. Vendor development to produce low-cost laser diode bars and diode coolers for HELSTF is ongoing. In support of a Laboratory Directed Research and Development (LDRD) project, LS\&T is also investigating a highpower Yb:YAG thin-disk laser for possible tactical weapons applications.

\section{Low-Cost and Reliable Solid-State Laser and Optical Material for AVLIS}

To further reduce the capital and operating costs of the potential future AVLIS plant, LS\&T continued to evaluate low-cost solidstate lasers and optical materials for AVLIS. In 1998, LS\&T developed a tunable, linenarrowed all-solid-state fiber laser system for AVLIS as a possible replacement for the dye master oscillator currently planned for a plant. By frequency summing the output from a diode-pumped $\mathrm{Yb}$ :silica fiber with that of a Nd:YAG laser in a periodically poled lithium niobate crystal, LS\&T successfully generated over $50-\mathrm{mW}$ output in the visible range. The overall system is very compact and reliable and can be manufactured at low cost. LS\&T scientists are also exploring new optical materials that can be used for frequency doubling under noncritical phase-matching conditions using innovative inorganic crystals with chemical structure similar to that of Gd-COB.

\section{Diode-Pumped Solid-State Laser for IFE}

Flashlamp-pumped Nd:glass lasers are ideal for demonstrating fusion, but MJclass, repetition-rated lasers with higher electrical efficiency are required for driving an inertial fusion energy (IFE) power plant. In 1998, LS\&T completed facility construction for a diode-pumped solidstate laser (Mercury), which will be the first of a new generation of laser drivers for high-energy-density physics and inertial confinement fusion. The Mercury laser is based on gas-cooled, diodepumped, crystal laser technology. The current design has several unique features over that of the flashlamp-pumped systems: (a) employing near-sonic helium to cool the laser slabs, (b) using highpower and efficient laser diode arrays as a pump source, and (c) utilizing Yb-doped strontium fluoroapatite (Yb:S-FAP) as the lasing media. Yb:S-FAP has greater energy storage capability, has higher thermal conductivity than Nd:glass, and is an ideal material for fusion applications. High-power laser diode arrays with peak output irradiance near $1 \mathrm{~kW} / \mathrm{cm}^{2}$ were fabricated. Gas cooling of the amplifier slab was demonstrated, and several 
Yb:crystals have been grown for initial optical testing. Full operation of the Mercury facility is planned for 2001. When completed, it should deliver $100 \mathrm{~J}$ at $10 \mathrm{~Hz}$ with $10 \%$ efficiency.

\section{Petawatt Laser and Large-Aperture Diffractive Optics}

The Petawatt laser facility was in full operation in 1998. It routinely produced more than 500-J laser pulses at 500-fs and supported a series of experiments to evaluate the fast-ignitor concept, generate $\mathrm{MeV}$ fast electrons or $\mathrm{x}$ rays for radiography research, and produce ps-100$\mathrm{MeV} \gamma$-rays (at $5 \times 1020 \mathrm{~W} / \mathrm{cm}^{2}$ ) for nuclear physics experiments. One of the critical technologies enabling the generation of petawatt laser pulses was the manufacturing of largeaperture and high-damage-threshold diffraction gratings for chirped pulse compression. Using both holographic and direct digital patterning, LS\&T engineers successfully manufactured tens of large-aperture diffraction gratings as well as prototypical color separation gratings and kinoform phase plates for the NIF. LS\&T is also developing large-aperture Fresnel lenses for space applications, which have a number of inherent advantages over conventional lenses. They can be made very thin and lightweight, and they have a much greater tolerance to surface-figure aberrations compared to a mirror. In 1998, LS\&T developed a replicating process for fabricating Fresnel lenses for space-based applications. The aim is to eventually produce multimetersize Fresnel lenses using thin membrane. LS\&T engineers have also developed an
Alvarez lens pair to correct astigmatism in the AVLIS laser systems. (An Alvarez lens pair consists of two phase profiles fabricated on two separate optics that enable the introduction of a variable amount of secondorder aberration in the beam.)

\section{Femtosecond Lasers for Advanced Light Source Development}

Under the support of LDRD funds, the LS\&T Program is building a high-averagepower, high-peak-power femtosecond laser facility, FALCON, for advanced light source development. The goal of FALCON is to generate a 100-TW repetitively pulsed laser system that can deliver ultrashort pulses with energy $\sim 4 \mathrm{~J}$, a pulse width of $30 \mathrm{fem}-$ toseconds, at a repetition rate of $0.5 \mathrm{~Hz}$. When completed, LS\&T will integrate the output from FALCON with the $100-\mathrm{MeV}$ electron beam generated by the linear accelerator (Linac, located in the basement of Building 194) to produce ultrafast $\mathrm{x}$ rays for a number of experiments of importance to the Laboratory's Stockpile Stewardship Program. Major experiments include the measurement of the dynamical properties of materials under shock compression conditions. The FALCON laser currently produces 5-TW, femtosecond pulses at $10 \mathrm{~Hz}$. The beam transport system and final target chamber for laser-electron interaction are under construction. The goal in 1999 is to demonstrate laser-electron synchronization and to perform the scattering experiments using the 20-TW, 35-fs laser beam and Linac's 5-MeV electron beam.

\begin{abstract}
A fully automated femtosecond laser cutting machine developed by LS\&T, which will be installed and operated on the factory floor at the Y-12 plant. This turnkey laser system has an output of $15 \mathrm{~W}$ and can cut materials with very high precision, small kerf, and minimal heataffected zone.
\end{abstract}

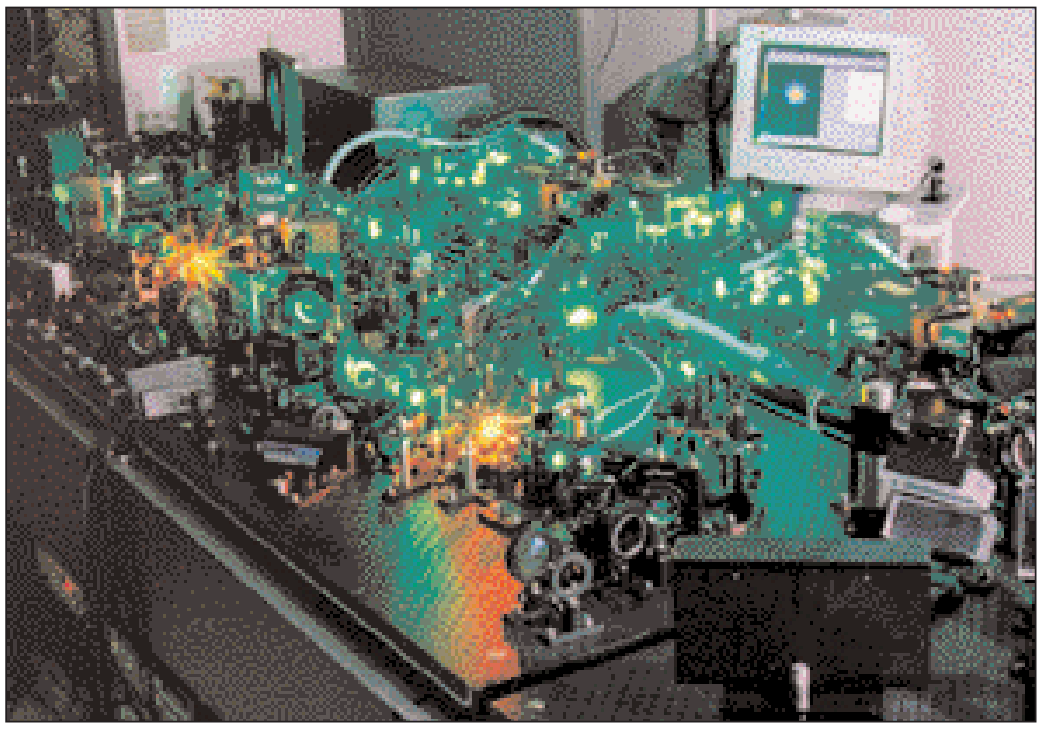




\section{Materials Processing Using High-Power Solid-State Lasers}

Spin-off developments of LS\&T's high-power solid-state laser technologies provided several unique machining tools for government and commercial needs. In 1998, LS\&T developed a fully automated femtosecond laser system for DOE's Y-12 Plant for use as a precision cutting machine in the Stockpile Life Extension Program. This high-repetition-rate Ti:sapphire laser has an output power of $15 \mathrm{~W}$ and can cut materials with very small kerf and with a minimal heat-affected zone. This precision cutting machine, a first of its kind, is currently being used daily on Y-12's factory floor as a utility. Several U.S. auto and aerospace companies are also working with LS\&T to develop short-pulse laser systems for precision machining of high-value components. High-quality thin films were also produced using the femtosecond laser as an ablation source. The high-energy plasma generated during the ablation enables the deposition of smooth films without the presence of particulates. LS\&T scientists were able to deposit high-quality films, such as diamond-like carbon, on various substrates at a high rate.

Under a Cooperative Research and Development Agreement partnership, LS\&T developed a high-energy pulsed laser system for the Metal Improvement Company, Inc., for use as a shock-peening tool for treatment of metal surfaces. In the peening process, the output of a pulsed high-energy laser (AITtype laser with an output of $100 \mathrm{~J} /$ pulse and pulse duration of $20 \mathrm{~ns}$ ) is condensed to approximately $200 \mathrm{~J} / \mathrm{cm}^{2}$ and is directed onto the surface of the work pieces. With an appropriate absorptive/insulating coating and a thin overlay of transparent material, a highpressure shock wave of 10,000 atmospheres $(150,000$ psi) can be generated across the metal surface. This shock treatment process induces deep residual compressive stress, which results in improved resistance to fatigue, galling, and stress corrosion. The shock-peening process can potentially be used by the aerospace industry to build safer, more reliable, and longer-lasting jet engines, helicopter gears, landing gears, and airframe structures. An important DOE application may be in enhancing corrosion fatigue resistance for nuclear waste storage containers. Laser treatment will also result in improved lifetime and reliability for many medical components, such as replacement of hip joints. By eliminating fatigue failure in orthopedic implants, one could improve the healing success of bone fractures. LS\&T's high-power and high-energy solid-state laser technologies allow for the first time high-throughput implementation of laser shock processing.

\section{Solid-State Laser for Active Remote Sensing}

In partnership with LLNL's Nonproliferation, Arms Control, and International Security (NAI) Directorate, LS\&T has developed a high-repetition-rate, frequency-agile, solidstate differential absorption lidar (DIAL) system for airborne chemical remote sensing. Tunable output in the mid-infrared region is generated by an optical parametric oscillator (OPO), using periodically poled lithium niobate crystals as the nonlinear material and a diode-pumped Nd:YAG laser as the pump source. Frequency tuning is achieved by changing the angle of the pumping beam in the OPO using an acousto-optics beam deflector. LS\&T successfully demonstrated stable output of $3 \mathrm{~W}$ at $10 \mathrm{kHz}$ and wavelength tunability at the 3.2- to $3.6-\mu \mathrm{m}$ region. A prototype laser system has been built and will be mounted on an Air Force C-135 aircraft for airborne field tests in 1999. This will be the first demonstration of a frequencyagile, solid-state lidar system for simultaneous detection of multiple chemicals.

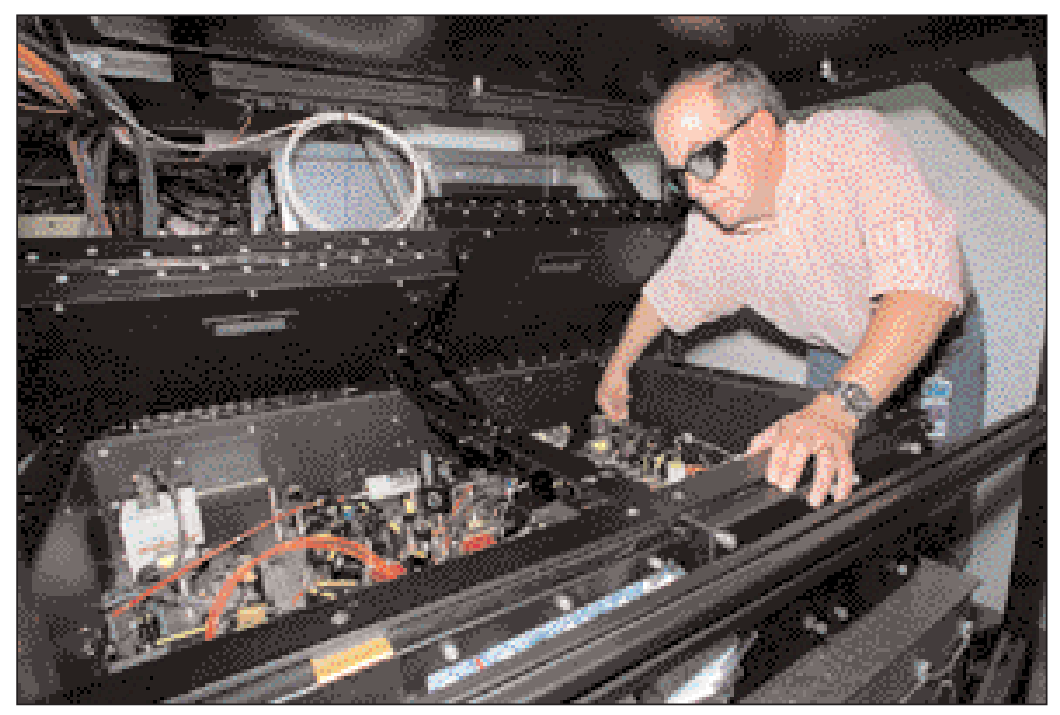

A compact, high-repetition-rate, frequency-agile, solid-state DIAL system ( $3 \mathrm{~W}$ at $10 \mathrm{kHz}$, tunable $3-4 \mathrm{~mm}$, optical parameter oscillator) for airborne chemical sensing experiments. 


\section{InTormation Jicience and I'ecillology frogriml}

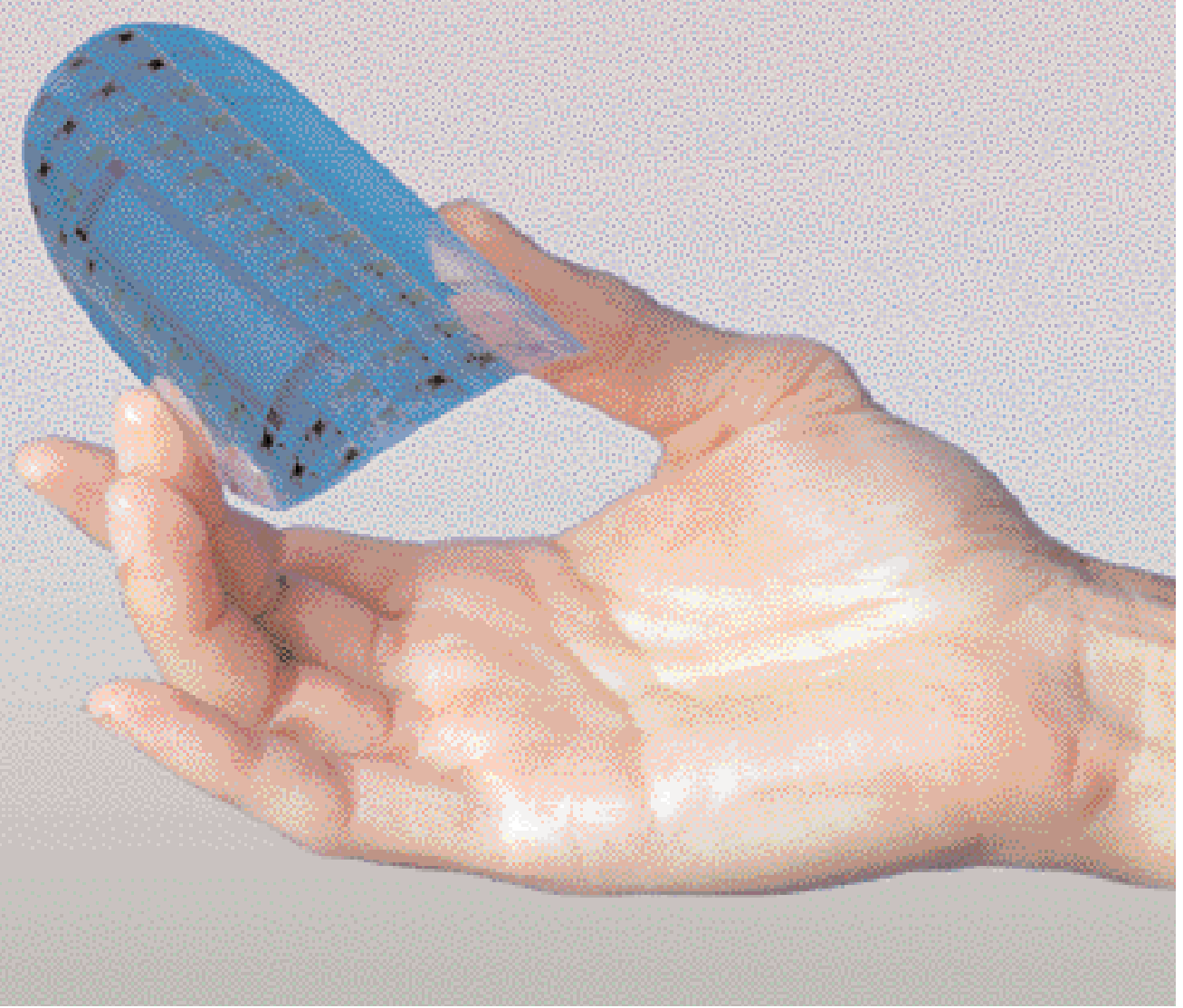

Four-inch-diameter flexible polyester substrate containing transistors, circuits, and pager displays.

\section{7}

he mission of the IS\&T Program in the Laser Directorate is to perform long-range research in imaging and information technology in support of DOE's future needs by leveraging and enhancing the capabilities of the information technology infrastructure within the United States. The health and security of the U.S. weapons stockpile, and on a larger scale, the economic well being of the nation itself is predicated on our country's leadership in information technology. The role of the IS\&T program is to assist in securing this lead in the international arena.

IS\&T's success relies on close partnership with industry, both the public and private sectors; academia; as well as other government agencies. Industry guides us in defining those program areas that are relevant to their long-range vision, sets the ground rules of a competitive environment, and aids in technology commercialization. The University of California affiliation helps to maintain a scientific level of excellence and serves as a training ground for future research scientists and program leaders. Collaborations with the DoD, National Aeronautics and Space Administration, National Institutes of Health, and other technology-driven agencies ensure that IS\&T technologies will permeate into application zones as far reaching as astronomy and health sciences. 
IS\&T drives four principal technology areas in achievement of its mission:

- Development of advanced semiconductor and micromagnetic manufacturing technologies.

- Development of photonic devices for optical sensing, transmission, and logic.

- High-resolution imaging technology development from microwaves to extreme ultraviolet wavelengths.

- Design and fielding of adaptive optics systems for correction of laser beam aberrations and for astronomical telescope image correction.

\section{Extreme Ultraviolet Lithography}

The largest project within IS\&T is Extreme Ultraviolet Lithography (EUVL) — a new lithographic technology for the fabrication of microelectronic circuits, championed and developed by LLNL, SNL, and Lawrence Berkeley National Laboratory. A consortium of Intel, Motorola, Advanced Micro Devices, and Micron Technologies is currently funding work at the three laboratories under a three-year, \$250M Cooperative Research and Development Agreement. SEMATECH, an international consortium of semiconductor manufacturers, recently selected EUVL as the most promising of four proposed new lithography technologies for the next decade.

EUV light is capable of imaging features as small as $25 \mathrm{~nm}$, providing a path towards the fabrication of the "ultimate" integrated circuits considered viable on silicon substrates. The first commercial application of EUVL will be at around 70-nm feature size in 2003, according to the recent Semiconductor Industry Association road map. The new technologies described below are being transferred directly into the private sector to facilitate commercialization of EUVL.

\section{EUV Optics and Optical Systems}

EUVL tools require reflective optics made to near-atomic-scale precision. Mirrors are typically off-axis aspheres, manufactured of low-expansion glass. Each of the mirrors must be mounted, assembled, and aligned to submicron tolerance in the lithographic camera to maximize the imaging efficiency and minimize distortion.

\section{EUV Thin Films/Coatings}

The IS\&T Program has developed optical coatings that reflect EUV light close to the theoretical limit of efficiency, far more uniform than ever made before. The multilayer coatings for EUVL systems typically consist of alternating layers of molybdenum and silicon $(\mathrm{Mo} / \mathrm{Si})$ or molybdenum and beryllium (Mo/Be). IS\&T has made $\mathrm{Mo} / \mathrm{Si}$ and $\mathrm{Mo} / \mathrm{Be}$ multilayers with greater than $65 \%$ reflectivity of EUV light. Mirror-to-mirror wavelength match is better than $0.01 \mathrm{~nm}$, and coating thickness variation is less than $0.1 \%$ across $200-\mathrm{mm}$ (8-in.) substrates.

\section{Metrology at Near-Atomic Dimensions}

High-accuracy metrology tools are required for fabrication of precision EUV optics. IS\&T has developed a new type of interferometer that has subnanometer absolute accuracy, arguably the most accurate interferometer in the world, capable of measuring optical surfaces to better than one atom of average deviation from a perfect surface.

\section{EUVL Masks}

The patterns that are projected on the wafers by the optical system must be made nearly defect-free (fewer than 0.01 defects per $\mathrm{cm}^{2}$ ) so that the chips made from the images will produce working circuits. IS\&T has developed technologies to produce low-defect blanks for these masks as well as technologies needed to detect sparse submicron defects on large fields (wafers up to $200-\mathrm{mm}$ diameter).

\section{Recent Experiments}

The IS\&T Program has assembled a prototype imaging camera that has optical quality beyond that achieved by any other existing optical system. This camera has produced circuit features as small as $50 \mathrm{~nm}$.

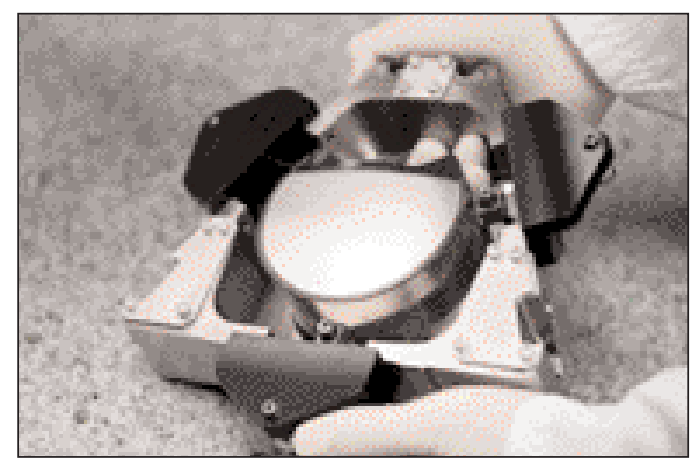

EUV optic coated and mounted, ready for use in a lithographic camera. 
Photograph of 50-nm, 60-nm, and 70-nm circuit features produced by prototype imaging camera.
Uncorrected (left panel) and corrected (right panel) focal spots from the Beamlet experiment, a singlebeam prototype of the NIF, demonstrating the necessity of adaptive optics for the NIF.

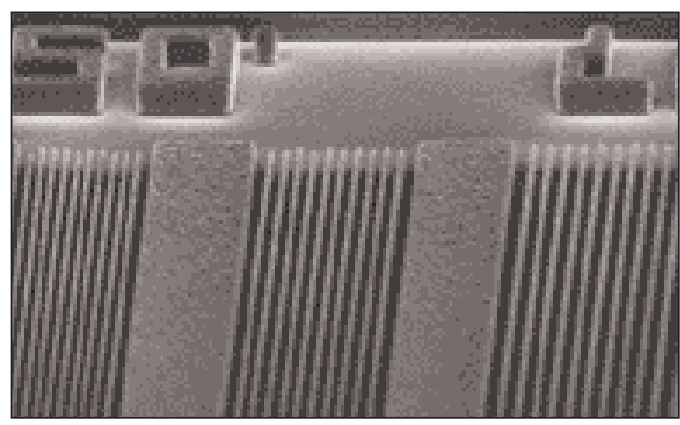

\section{Adaptive Optics}

The IS\&T Adaptive Optics Group develops and tests a broad range of advanced wavefront control technologies, currently focusing on laser and astronomical systems.

\section{Laser Systems}

Adaptive optics are used to correct time-varying aberrations in optical systems. Most highperformance laser systems at LLNL, including the NIF, require adaptive optics to maintain required beam quality.

The goal of a current project on high-resolution wavefront control is to use advanced devices, such as Liquid Crystal (LC) Spatial Light Modulators (SLMs) or Micro-ElectroMechanical Deformable Mirrors along with advanced wavefront sensing algorithms to provide capability for wavefront control with a large number of phase control elements. Initial lab experiments using LC SLMs and a Hartmann wavefront sensor have demonstrated successful wavefront control with more than 1000 elements.

The goal of the project on intracavity wavefront control is to correct aberrations in a high-average-power laser that uses a solid-state "heat capacity" amplifier with no heat removal during active operation. This laser project is being funded by the DoD for potential use at the High Energy Laser Systems Test Facility in White Sands, New Mexico.

\section{Astronomical Systems}

Images of astronomical objects from groundbased telescopes are blurred by aberrations

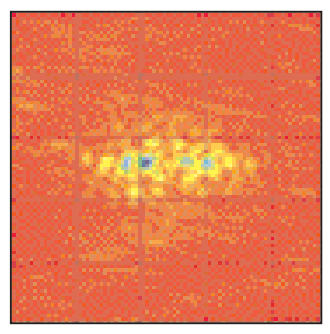

caused by turbulence in the Earth's atmosphere. Adaptive optics compensates for these aberrations and allows imaging with resolution limited only by the diameter of the telescope. For the largest astronomical telescopes, this can lead to a tenfold or greater improvement in resolution.

To correct for the aberrations due to turbulence, an adaptive optics system uses light from a reference source above the turbulence to sense the wavefront errors. A bright star can be used for this purpose; however, there is often no bright star near enough to a given astronomical object to be used for the reference. In this case, it is possible to use a laser to create a suitable beacon by resonance fluorescence of sodium atoms located in a layer at an altitude of $\sim 90 \mathrm{~km}$ in the Earth's mesosphere. LLNL has pioneered the use of pulsed dye laser technology for the production of sodium-layer LGS systems.

The Lick Observatory system is the first high-order adaptive optics system to successfully utilize a sodium-layer LGS. The Lick system is based on a 127 -actuator deformable mirror, a Hartmann wavefront sensor equipped with a fast-framing, lownoise charge-coupled device camera, and a pulsed solid-state-pumped dye laser tuned to the atomic sodium resonance line at $589 \mathrm{~nm}$. Tests of this system have produced stellar images recorded at a wavelength of 2 microns, corrected to over $40 \%$ of the theoretical diffraction-limited peak intensity.

The Keck Observatory adaptive optics system in Hawaii is the most powerful astronomical system on the world's largest telescope. The first engineering results from the Keck system using natural stars have produced images recorded at a wavelength of 1.6 microns that are corrected to over $30 \%$ of the theoretical diffractionlimited peak intensity. The laser system is currently being tested in the lab at the Keck Observatory and is scheduled for deployment on the telescope in 2000.

\section{Microwave Sensors}

The Microwave Sensor Program is based on Micropower Impulse Radar (MIR) technology combined with high-performance signal and image processing to solve problems in imaging radar, precision ranging and velocity diagnostics, and high-sensitivity motion detection. MIR is a spin-off invention from LLNL's laser fusion diagnostics work in tran- 


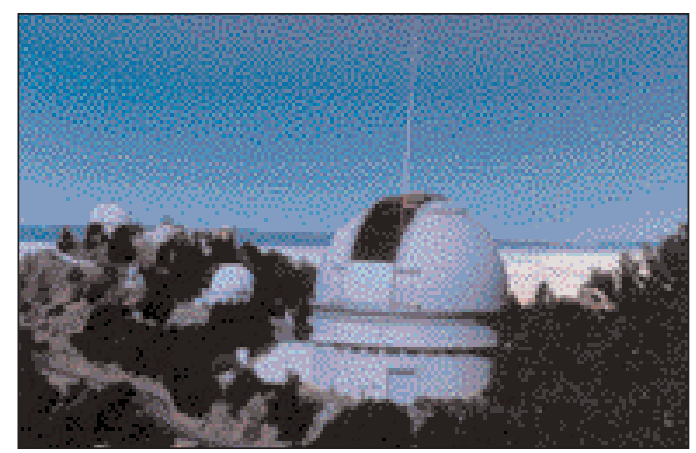

Beam from the Lick LGS system projected out of the dome of the 3-meter Shane Telescope at the Lick Observatory located on Mt. Hamilton, California.

sient digitizers. Microwave sensor technology has been applied to numerous uses, ranging from an electronic dipstick to measure fluid levels in automobiles to land-mine detection.

Based on emitting and detecting very lowamplitude voltage impulses, MIR has a sensitive detection window for accurate ranging that can be varied over time to provide radar return information at various ranges. The hardware package is very small (handheld), made of inexpensive electronics, and has extremely low power requirements.

Average emissions are well below $10 \mathrm{~mW}$ and are spread over several gigahertz, virtually eliminating both interference and interception. In contrast to conventional radar, which uses continuous microwave energy to detect objects over many miles, impulse radar transmits ultrashort electromagnetic pulses that allow the detection of objects at very short ranges. Impulses, producing a wide band of frequencies, generate a great deal of information about detected objects at high resolution and accuracy. The echoes of these pulses are measured by an extremely sensitive receiver that is set for a detection range of a few centimeters to many tens of meters. System components also include timing circuitry, a signal processor, and antennas. Together, they determine system range, directionality, and how well materials such as concrete, wood, and other nonmetallic materials can be penetrated.

Such microwave sensors are being used in a wide variety of applications, including real-time helicopter blade position measurement, velocity diagnostics in experiments on aging explosives, and perimeter security systems.

\section{Photonics}

The use of optical photons, instead of electrons, to manipulate information offers many advantages, including the ability to process information at very high data rates. IS\&T achieves this high-data-rate aspect through the application of novel femtosecond optical techniques in the time domain as well as through the use of multiple optical wavelengths simultaneously. This requires the development of novel materials, stateof-the-art photonic device fabrication, and unique system implementations. IS\&T applies these technologies to applications that are crucial to national security missions and have significant commercial impact. In particular, the IS\&T Program emphasizes high-speed instrumentation and highbandwidth communications for ultrascale computer interconnects.

\section{Photonic Materials}

IS\&T's photonic materials development effort focuses on exploiting the unique opti$\mathrm{cal}$ and electrical properties of nanoscale materials: specifically quantum dots and macromolecules. The Program has developed unique organic light-emitting diodes for flat-panel displays (FPDs); demonstrated broad wavelength tunability of optical emission based on quantum confinement in nanostructured Si, Ge, ZnSe, and GaN; and demonstrated that fullerene (a soccerball-shaped macromolecular form of carbon) exhibits an extraordinarily high optical nonlinearity suitable for ultrafast all-optical switching applications.

The IS\&T approach is a combination of fundamental measurements, unique material processing, and innovative device fabrication. The fundamental measurements toolbox includes absorption, photoluminescence, and femtosecond spectroscopies as well as an LLNL-developed optical nonlinear measurement technique-Antiresonant Ring Interferometric Nonlinear Spectroscopy.

This materials work supports a wide range of applications from FPDs and blue emitters to all-optical gating for high-speed instrumentation and ultrahighspeed logic functions.

\section{Optical Interconnects for Computing}

IS\&T optical interconnects work is focusing on improvements in bandwidth, concurrency, and latency through the development of array-based optical transmitters and 
Scanning electron microscopy micrograph showing a subset of a VCSEL array. VCSELS are state-of-the-art lowthreshold current (<1 mA) oxideconfined structures.

An optical field simulation of the time lens demonstrating temporal magnification of a signal consisting of three pulses. A $\times 100$ time lens with 100-fs resolution and excellent fidelity has been demonstrated.

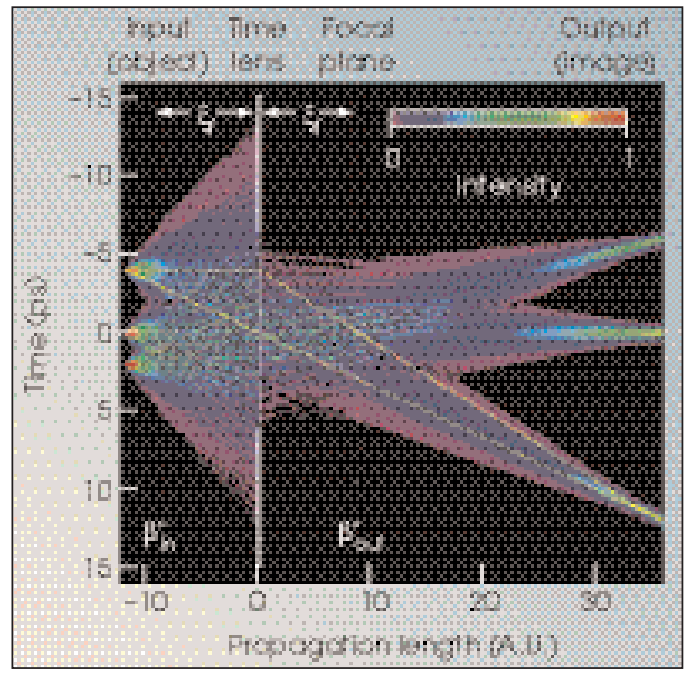

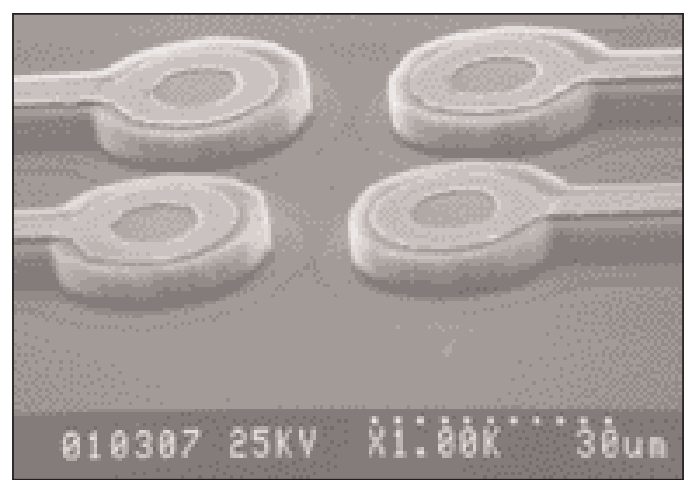

receivers. In particular, researchers have made significant progress in the development of two-dimensional arrays of Vertical Cavity Surface Emitting Lasers (VCSELs).

The two-dimensional VCSEL arrays are unique-in one dimension of the array the wavelength varies in a regular fashion. This enables wavelength division multiplexed (WDM) parallel optical interconnects (POIs). POIs are data channels in which information is transmitted in a bit-parallel way along ribbon fiber arrays. These WDM POIs offer significant bandwidth and concurrency (multichannels simultaneously), while also enabling powerful new interconnect architectures that are based upon wavelength source routing.

\section{High-Speed Instrumentation}

When signals are in the optical domain, entirely new possibilities arise for their manipulation and exploitation. Instrumentation with extraordinary characteristics becomes possible-new sensors of physical phenomena, all-optical gating/logic, and new means of high-speed signal recording. Not surprisingly, one of the key attributes of this new photonic instrumentation is the often extremely high bandwidth that is attainable. For instance, the FemtoScope development effort focuses on the development of an instrument that is capable of recording single-transient signals with temporal resolutions of 100 fs. One of the approaches being pursued is called the time lens. By exploiting the analogy between dispersion and diffraction, it is possible to create the temporal equivalent of a spatial microscope that magnifies images. This time microscope effectively "stretches-out" the temporal axis of a signal under consideration by imparting a quadratic phase chirp on the optical signal. By thus slowing the signal down, it will then be possible to record it with more conventional techniques.

\section{Magnetic Storage}

IS\&T is researching new technologies that can dramatically increase magnetic disk storage capacity. In conventional bit storage schemes, high-density arrays of magnetic stripes are written onto a spinning disk. As the bit distance per track continues to decrease, the intrinsic noise associated with the reading head overwhelms the desired signal from any one bit. This interbit "transition noise" dominates the read signal for aerial densities greater than $10 \mathrm{~Gb} /$ in. $^{2}$. The primary goal of IS\&T's research in this area is to circumvent this limitation by developing a transition noise-free media.

One promising technique to overcome the signal-to-noise problem in magnetic storage is to replace the magnetic stripes by patterned arrays of individual dots. IS\&T's research team has fabricated submicron elliptical cylinders by interference lithographic techniques to produce magnetically uniform arrays that display simple magnetic field reversal response.

In parallel, IS\&T has developed a powerful and flexible micromagnetics numerical simulation computer code that is being used to analyze the magnetic field response of the dots in these arrays. This code can also be used for fundamental studies of magnetization dynamics and has been experimentally validated through the design optimization and fabrication of read head sensors. Planned extensions to the micromagnetics simulation code are the inclusion of current heating and self-field effects.

To achieve the storage industry's aggressive goal of $100 \mathrm{Gbit} /$ in. $^{2}$ areal density, substantial improvements in the write-head performance will be required. Advanced write-head pole materials must possess large moments, reasonable permeability, near-zero magnetostriction, and high resis- 
tivity. Robust corrosion properties are also important for the writer to survive fabrication processes. Ongoing research within IS\&T to address these challenges is focusing upon thin-layer combinations of novel materials using both the material properties and thicknesses to optimize performance.

\section{Future Directions}

Several extensions of this research are being actively pursued. Preliminary investigations indicate that the interference lithography process can be extended to nearly 100 Gdots/ in. $^{2}$, in a more useful format that retrofits into the current disk-drive architecture. Thus, dot array fabrication may be a viable replacement for conventional storage media.

IS\&T is also investigating both spin-valve and magnetic tunnel junctions for application to magnetic random access memory devices (MRAMs). IS\&T's strengths in multilayer deposition, micromagnetic simulation, and electronic processing have combined to define a unique capability for fabricating and integrating submicron magnetic memory elements on integrated circuits for next-generation, radiation-hardened, and nonvolatile memory applications. Since the magnetoresistive effect scales inversely with bit size, MRAMs could potentially represent the next breakthrough in memory technology with fast access times, low power consumption, unlimited readwrite cycles, and a thousand-fold storage advantage beyond today's mainline dynamic random access memory chips.

\section{Flat-Panel Displays}

The development of displays on plastic substrates, fabricated by roll-to-roll processing techniques, offers an exciting alternative for the production of large lightweight FPDs. The FPD industry reached an important milestone in 1998 through the production of 15- to 18-in. liquid crystal displays to replace cathode ray tubes in computer monitors. The rapid evolution of FPD technology will soon bring high-resolution visualization of complex computer simulations or experimental diag- nostics to the desktop. However, glass-based FPDs are reaching the limit of affordability with respect to size, with 40- to 50-in. plasma display panels still costing over $\$ 10,000$ and being far too heavy to be hung on a wall.

Light-emitting polymer (LEP) technology seems to be ideally suited for the next generation of FPDs, but it cannot reach its full potential without the aid of active-matrix electronic backplanes. The IS\&T semiconductor processing group provides such a capability by fabricating polysilicon thin-film transistors on polyethylene terephthalate (PET) — a thin, flexible, and rugged polyester plastic that can be rolled up, folded, or bent into practically any shape. PET is an ideal substrate for low-cost, paper-thin flexible displays. Fabrication of transistors at low temperatures, required for compatibility with such substrates, is made possible using a pulsed laser process developed at LLNL to both crystallize and dope amorphous silicon thin films deposited at less than $100^{\circ} \mathrm{C}$. Performance of transistors made using this process compare favorably with those in a laptop computer's display. For example, the electron mobility for these polysilicon transistors is 100 times greater than the amorphous silicon transistors presently being used in commercially available FPDs. Using the improvement in electron mobility offered by laser conversion of amorphous silicon to poly-Si, the high currents required by LEP pixels can be controlled with driver voltages less than $10 \mathrm{eV}$.

The ability to fabricate drive circuitry on plastic display backplanes opens the door not only to a multitude of DoD applications but also to a plethora of low-cost consumer products of the future.
Hysteresis loop and magnetic force microscope comparison with simulation. 


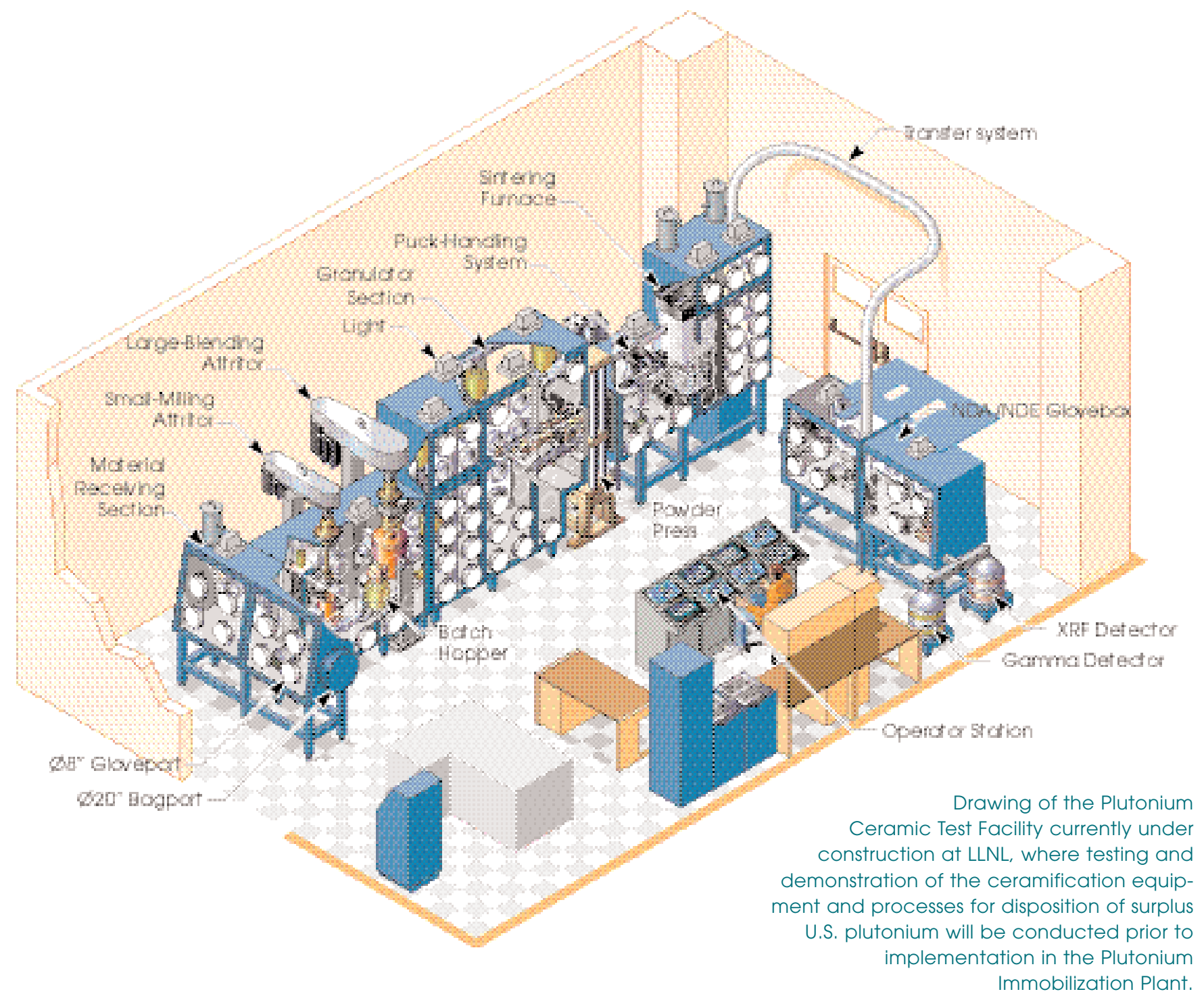

the shortage of plutonium for weapons had become an urgent concern, and the DOE funded the Laboratory to build and demonstrate full-scale production prototype hardware, including full-scale chemical processing and isotope separation systems. LLNL completed this task by the late 1980s. The DOE also directed the Laboratory to work with its production contractors on the design of a plutonium isotope separation plant. However, with the sudden end of the cold war in 1989, the country's need for plutonium production disappeared. Plans for the SIS plant were halted, and the system at LLNL was placed in standby.

LLNL's work with plutonium in the SIS Program had greatly increased the Laboratory's expertise in nuclear materials, and the Laser Programs had also gained experience collaborating with the DOE's Production Plants. Thus, following the SIS closeout, LLNL was able to secure funding to apply its expertise in nuclear materials in support of the DOE's production complex. Laboratory scientists and engineers applied several of the Lab's advanced processing technologies to the ongoing cleanup of DOE's production complex and helped pave the way for a new, more modern complex. Through this, and a number of follow-on programs, the Laser Programs have successfully maintained the Directorate's core excellence in nuclear materials and today support a large number of efforts organized under the Strategic Materials 


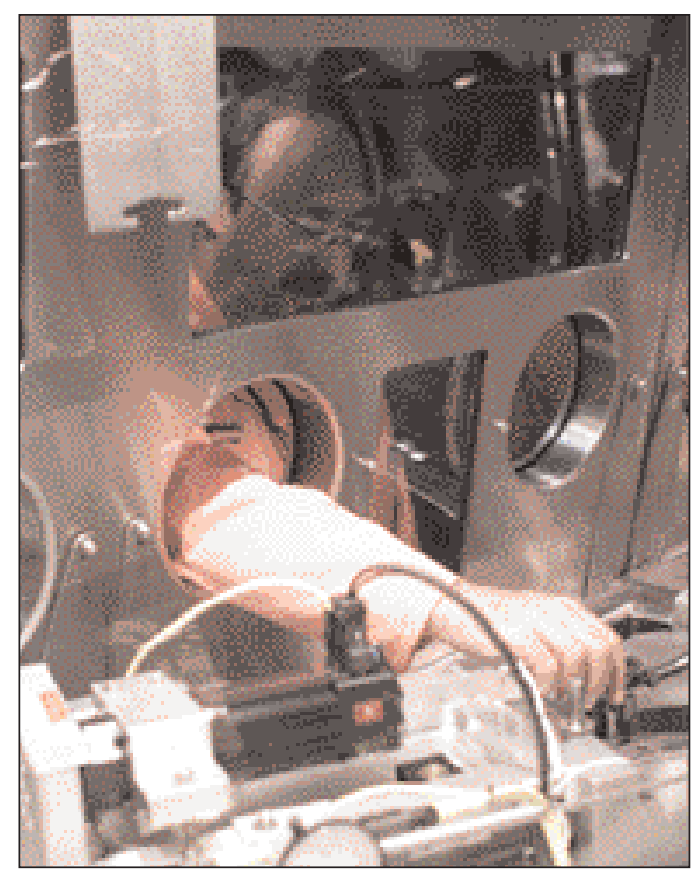

Technician making an adjustment to ARIES hardware, developed to split apart retired nuclear weapon pits to recover the plutonium.
Applications Program (SMAP), which was formally created as a separate program within the Laser Directorate in 1996.

SMAP projects today are engaged in developing technologies for processing, manufacturing, and storing nuclear materials. It is also developing advanced techniques for the safe and secure disposition of excess nuclear materials from the DOE's inventory.

\section{ARIES}

SMAP is working with LANL to develop the Advanced Recovery and Integrated Extraction System (ARIES) to recover plutonium from retired or excess nuclear weapons. SMAP has developed the hardware to cut apart the returned pits and recover the plutonium from within. This excess plutonium will then be immobilized in ceramic pellets for disposal or used as fuel in civilian nuclear reactors. LLNL is developing the prototype hardware, testing the systems, and designing processing modules for installation and use at LANL.

During 1998, SMAP also used the ARIES prototype hardware developed at LLNL to help DOE complete the decommissioning of the Rocky Flats plutonium pit plant. This site, now named the Rocky Flats Environmental Technology Site (RFETS), has large inventories of plutonium in various forms that need to be removed from the site and processed and packaged for safe and secure storage. To help in this effort SMAP technicians are processing pits and other plutonium parts from RFETS to recover the plutonium and are repackaging it in modern storage containers in preparation for shipment to a long-term storage site.
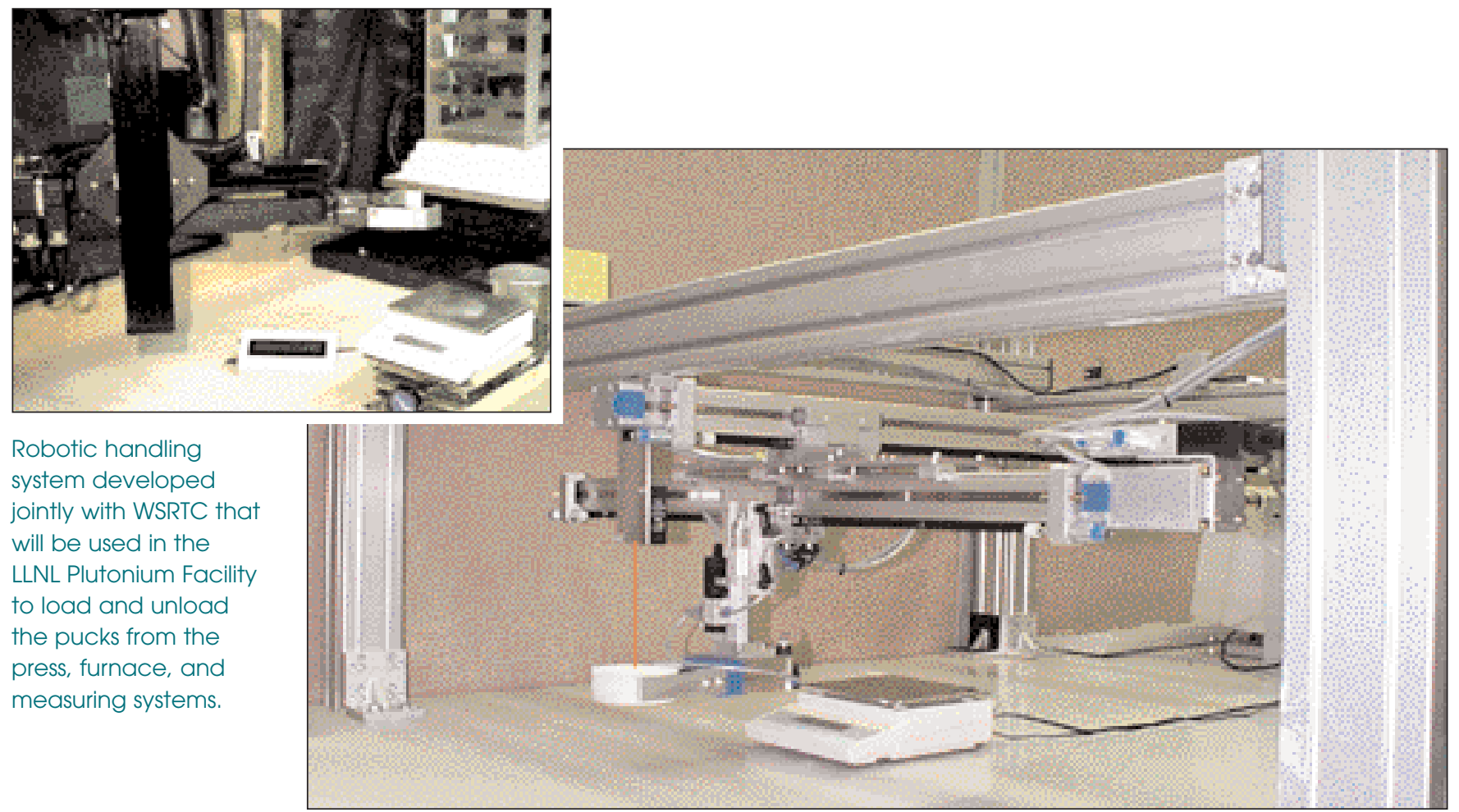

Robotic handling system developed jointly with WSRTC that will be used in the LLNL Plutonium Facility to load and unload the pucks from the press, furnace, and measuring systems.

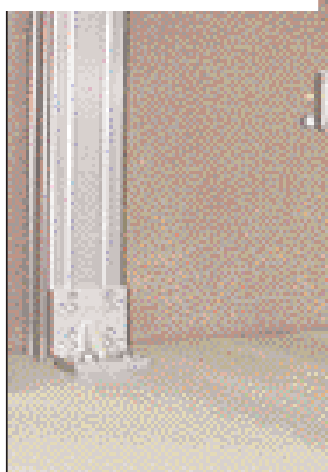

The first proof-of-concept design for automatic measuring of plutonium puck characteristics. This functionally prototypical robotic system is being developed jointly by LLNL and WSRTC engineers. 


\section{Plutonium Immobilization}

SMAP is collaborating with LLNL's Nonproliferation, Arms Control, and International Security (NAI) Directorate in DOE's Fissile Material Disposition Program to develop alternatives for disposal or longterm storage of excess nuclear materials. In the aftermath of the Cold War, the United States and Russia have agreed to large reductions in their nuclear weapon stockpiles and their inventories of special nuclear materials such as plutonium. To accomplish this task, the DOE has selected two options for the storage and ultimate disposition of surplus plutonium in accordance with this national policy. These options are to either immobilize the plutonium in ceramic pucks for disposal or to consume it as fuel in civilian nuclear reactors. Russia and other nations with similar interests or experience are collaborating with us in this effort.

LLNL has been selected by DOE as the lead laboratory to develop the technology to immobilize, or chemically "lock up," excess plutonium in specially designed ceramic pellets. This ceramification process converts the oxides of plutonium into minerals whose natural analogs have contained related elements for thousands of years. Engineers and scientists in the Plutonium Immobilization Program (PIP) effort are developing prototype equipment and evaluating processing parameters to grind, mix, blend, and transport the raw and processed material. "Locking up" the plutonium in ceramic makes the material environmentally safe for long-term disposal in an underground repository.

LLNL is working closely with the Westinghouse Savannah River Technology Center (WSRTC), Argonne National Laboratory, the Pacific Northwest National Laboratory, and the Australian Nuclear Science and Technology Organization in the PIP effort to deploy a plutoniumceramic immobilization plant in the coming decade. This plant is planned for construction at Savannah River and is scheduled for completion in 2007. Currently under construction at LLNL is a plutonium Ceramification Test Facility to develop

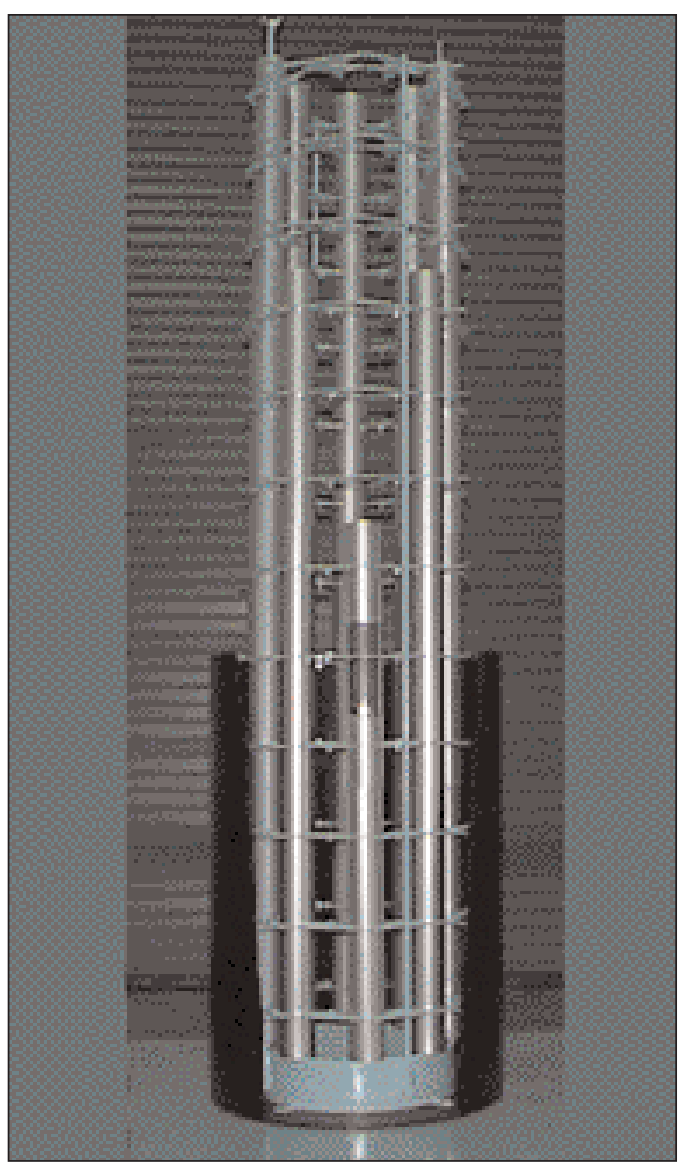

Canister in which sintered pucks will be placed. When fully loaded, the canister will be filled with glass containing high-level waste and shipped to the Defense Waste Production Facility. and test equipment and processes for the future plant. It is scheduled for completion in January 2000 and will be moved to the Plutonium Facility later that year.

\section{Laser Cutting Project}

Under the joint guidance of SMAP and LS\&T, the Laser Programs have developed a laser cutting technology to help disassemble nuclear weapons for DOE's Defense Programs. Using this technology will allow the reuse of high-cost components within the weapons, reducing both the cost and time when compared to conventional processes. This system, built and tested at LLNL in 1996 and 1997, was delivered, installed, and activated in 1998 at DOE's Y-12 Plant in Oak Ridge Tennessee. This laser is currently employed in a major DOE remanufacturing program. 


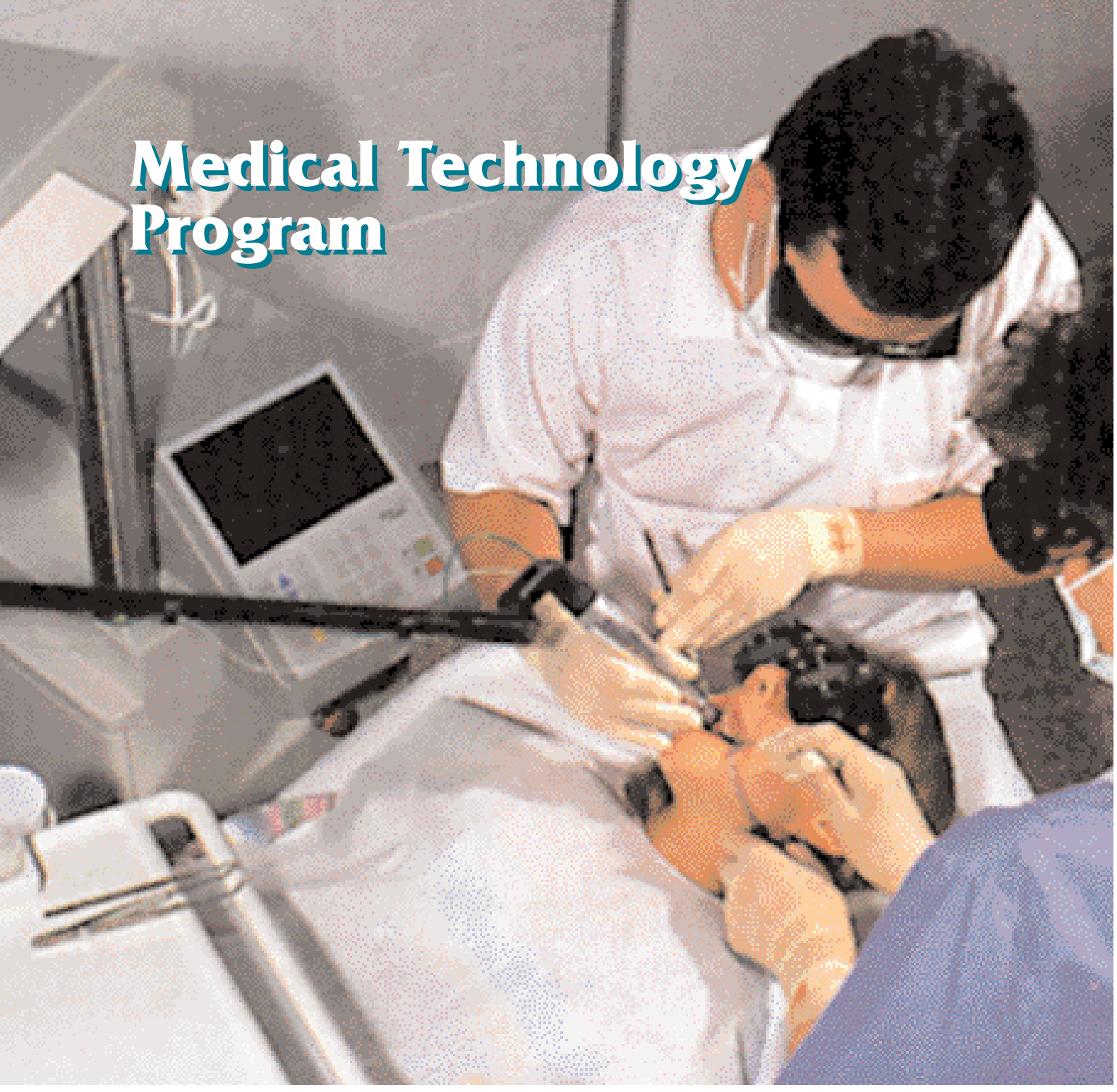

Dentist removing carious material with a laser delivered through an articulated arm. Future use of the ultrashort-pulse laser for medical applications requires a laser sized for the medical suite.

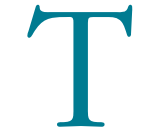

he creation of the Medical Technology Program (MTP) in 1997 brought together medical device research at LLNL as part of a broadly based program encompassing several disciplines across the Laboratory. Genomics, structural biology, and numerous bioscience projects continue in the Biology and Biotechnology Research Directorate. Forming MTP enabled cost-effective research and development of treatments for acute stroke, cancer detection and therapy, diabetes diagnostics, and therapy for other prevalent diseases of national importance. MTP is a collaboration among Engineering, Defense and Nuclear Technologies, and Laser Programs. 
Since the inception of medical device research at LLNL in 1994, over 50 projects have begun amounting to about $\$ 10 \mathrm{M} /$ year and currently involve over 30 scientists, engineers, and students.

\section{Dental Disease Diagnostic System}

MTP is developing state-of-the-art noninvasive high-resolution $(<20 \mu \mathrm{m})$ optical imaging systems based on Optical Coherence Tomography (OCT) for dental and other medical applications. MTP has detected small caries (early stage cavities) and structural abnormalities near reconstructions (fillings) without using ionizing radiation (x rays). The system is in early stage clinical evaluation. OCT utilizes a short-coherence-length broadband light source in an interferometric detection scheme to generate high-resolution crosssectional images of biological tissue. In a further improvement, the polarizationsensitive OCT system also measures the polarization state of the backscattered light, providing additional information about the state of the tissue. MTP has demonstrated the potential of polarization-sensitive optical coherence tomography (PS-OCT) for in vivo diagnosis of early, incipient dental caries. The PS-OCT system discriminates between normal and carious regions by measuring the polarization state of the back-scattered light, which is affected by the state of demineralization of the enamel. The figure shows PS-OCT images of the intensity (left) and polarization state (right) of the backscattered light. The polarization image clearly shows a region of demineralized enamel associated with a carious lesion. MTP has also demonstrated that this technique detects early lesions on both the facial and occlusal (biting) surfaces of the teeth. This technique should thus make early intervention possible, minimizing the need for drilling and the associated loss of structural integrity of the tooth. This system won an R\&D 100 award and is available for licensing.

\section{Karmanos Breast Cancer Screening Project}

The Ultrasonic Mammography Program at LLNL is a large project sponsored by the
Barbara Ann Karmanos Cancer Institute (KCI) to develop a new paradigm for breast cancer screening. The program is a $\$ 12$ million, three-year effort at LLNL organized as a Work for Others project. The project includes the design, construction, testing, and delivery of a fully 3-D, high-resolution automated ultrasonic scanner geared specifically towards early detection and classification of breast cancer tumors. There are three phases (one per year) of which the first and most critical phase is nearly complete. This first phase involves four independent major tasks that are designed to evaluate the overall feasibility of such a system, map out the expected system capabilities and limits, and specify the system design parameters. During the front-end hardware phase, MTP will design and fabricate ultrasonic transducer microarrays, procure existing ultrasonic microtransducer arrays, test and evaluate potential array technologies, and assess strategies for addressing large arrays. For the simulation part of phase I, MTP has modified existing LLNL wave propagation codes for use with ultrasound, constructed 2-D and 3-D numerical test objects, created a 3-D numerical ultrasound breast model, and generated simulated data sets with various numerical objects, array geometries, and imaging schemes. The image reconstruction involves the development of image reconstruction codes for three different imaging schemes in both transmission and reflection modes; the development of preprocessing methods to prepare raw data for reconstruction; and 2-D and 3-D image rendering,

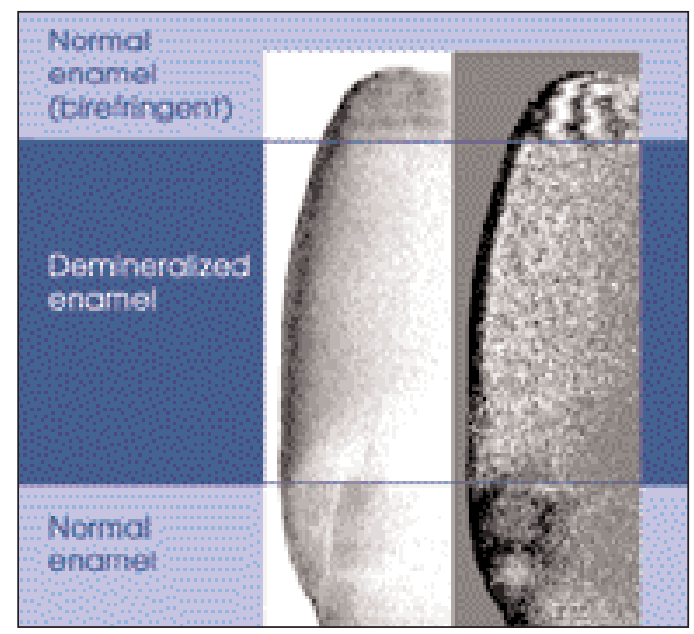

Polarization-sensitive Optical Coherence Tomography of a tooth showing a carious lesion. 


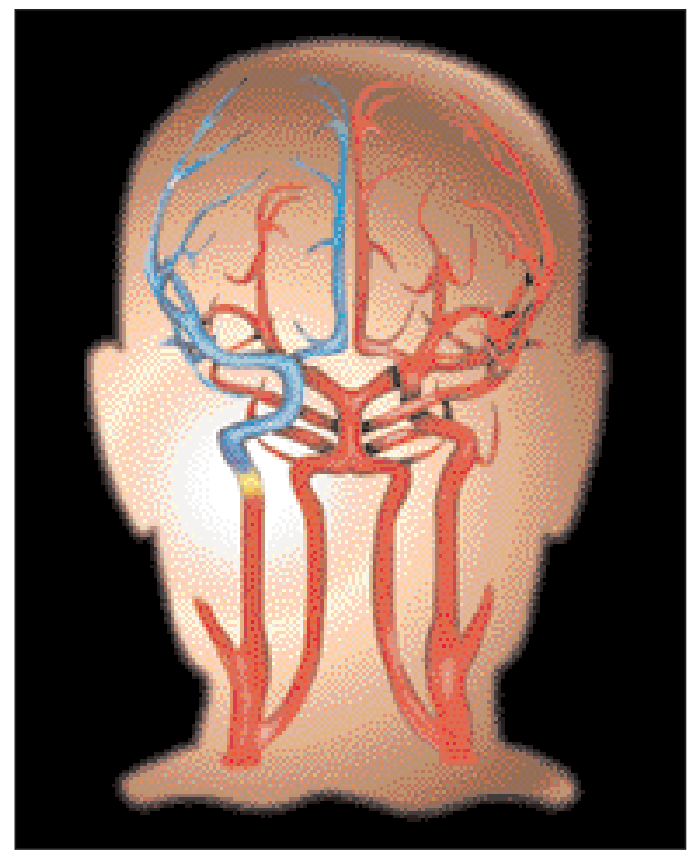

Illustration showing a blockage in the carotid artery, which is preventing blood flow to areas of the brain. LLNL's minimally invasive technique, EPAR, causes mechanical disruption of the occlusion and reestablishes blood flow to the brain. Stroke is the third leading cause of death in the United States. display, and manipulation. The final step in phase I, testing, begins with the construction of an ultrasonic scanner capable of synthesizing arbitrary array geometries, design and construction (or procurement) of ultrasound phantoms and test objects, and the acquisition of test data sets. The final delivery, a working prototype breast cancer screening device is scheduled for 2001.

\section{Endovascular Photo-Acoustic Recanalization (EPAR)}

LLNL research on an endovascular stroke treatment system has been successfully completed. Researchers at LLNL are attacking the problem of stroke with new tools to restore blood flow. Our minimally invasive technique, EPAR, involves coupling laser light into an optical fiber and delivering it to the occlusion through the use of a catheter. This causes mechanical disruption of the occlusion and reestablishes blood flow to the brain. The mechanism of interaction involves depositing laser energy into blood or a blood clot, creating an acoustic wave that is transmitted into the clot and, finally, formation of a vapor bubble that aids in the emulsification of the clot. This technology was licensed to EndoVasix, which continued cooperative development with LLNL through mid-1998. Since then, EndoVasix has begun early-stage human trials with this system. Also in 1998, LLNL researchers won a federal award for the transfer of this technology, important for the well being of the country.

\section{Light-Activated Endovascular Microgripper}

A second cerebral disease treatment system has been transferred to industry. The lightactivated microgripper is being used to treat aneurysms in the brain. Aneurysms are weak areas along an artery that balloon out, often causing symptoms by pressing on adjacent areas of the brain. Aneurysms also put the patient at risk for a hemorrhagic stroke. The device is a catheter-based system that deposits tiny metal embolic coils into the aneurysm, promoting a stable clot that allows the aneurysm to heal. The coils are deposited with the LLNL microgripper, which holds the coils firmly until light along the fiber-optic catheter causes the gripper to release the coils into the aneurysm. The key component to this medical device is a photomechanical microactuator that

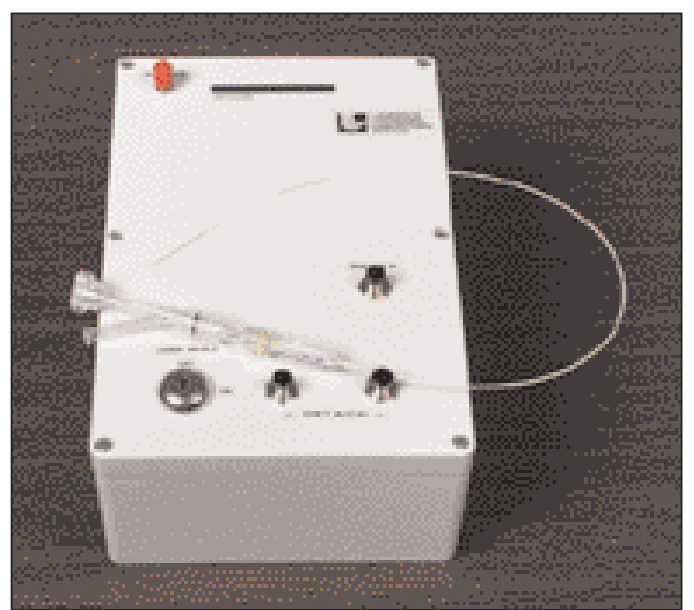

A prototype LAP device consisting of a diode laser, controlling electronics, and the "gripper" catheter. 
releases the coils when actuated with light. A fiber optic carries laser energy to a light-activated polymer (LAP). The LAP is a material in which the elastic modulus or "stiffness" can be reduced by three orders of magnitude when heated above a transition temperature. This softening is combined with engineered residual stresses in the actuator. When the light heats the LAP, in less than a second, it releases the embolic coil. The device has been transferred to Micrus, and is also in early stage human clinical trials.

\section{Continuous Glucose Monitor for Diabetes Treatment}

In collaboration with an industrial partner, MiniMed, MTP is developing a fluorescence-based sensor to continuously monitor the glucose levels for use in treating diabetes. Continuous glucose monitoring, when coupled with the existing MiniMed insulin pump, would form a biomechanical pancreas. This breakthrough could potentially improve the long-term health of the $>10,000,000$ diabetics in the United States. The device is based on the use of specially developed molecules that change their light-emitting properties when glucose is present.

These molecules have been successfully attached to tiny biocompatible polymeric membranes. A dime-sized membrane could be implanted just under the skin. By monitoring the light from the polymer, the glucose levels are inferred. To date, the device has been used in successful animal studies. This technology was featured at the DOE Medical Technology Exposition in Washington, DC.

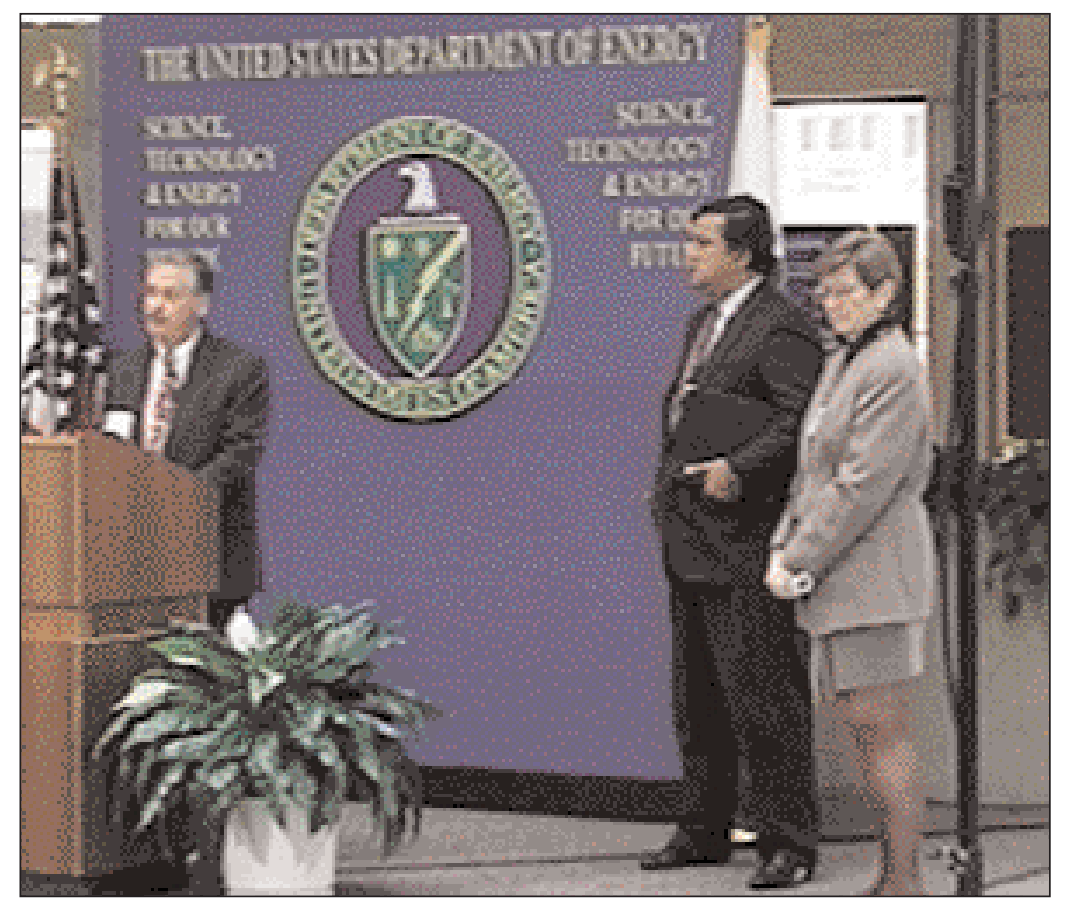

Steve Lane, MTP group leader for chemical sensors, addressing the DOE Medical Technology Expo in Washington, DC., about his group's work on diabetes treatment. Secretary of Energy Bill Richardson and Director of Energy Research Martha Krebs look on. 


\section{Awards}

\section{The R\&D 100 Awards}

Each year R\&D Magazine selects the 100 most technologically significant products and processes submitted for consideration and honors them with an R\&D 100 Award. Winners are chosen by the editors of the magazine and a panel of 75 experts in a variety of disciplines. Corporations, government laboratories, private research institutes, and universities throughout the world vie for this "Oscar" of applied research. The R\&D 100 judges look for products or processes that promise to change people's lives by significantly improving the environment, health care, or security. In the years between 1985 to 1998, the Laser Directorate has won 37 R\&D 100 Awards, placing it seventh in overall competition for all national organizations. In total, to date, the Laser Directorate has received 39 R\&D 100 Awards. Names in boldface print are members of the Laser Programs Directorate.

In 1998, Steve Azevedo, Scott Nelson, Tom Rosenbury, Holger Jones, Robert Stever, Tom Story, George Governo, Richard Gilliam, Greg Dallum, Pat Welsh, Mark Vigars, and Jose E. Hernandez from Lasers along with Jeff Mast, John Warhus, and Ming Liu from Engineering and Steve Chase of the Federal Highway Administration shared an award for the High-performance Electromagnetic Roadway Mapping and Evaluation System, or HERMES, a high-resolution, radar-based mobile inspection system for detecting and mapping defects in bridge decks.

Some of the road defects that can be detected with HERMES are concrete flaws, water damage, and delaminations. Additional possible applications include inspection of the top layers of highways and roads,

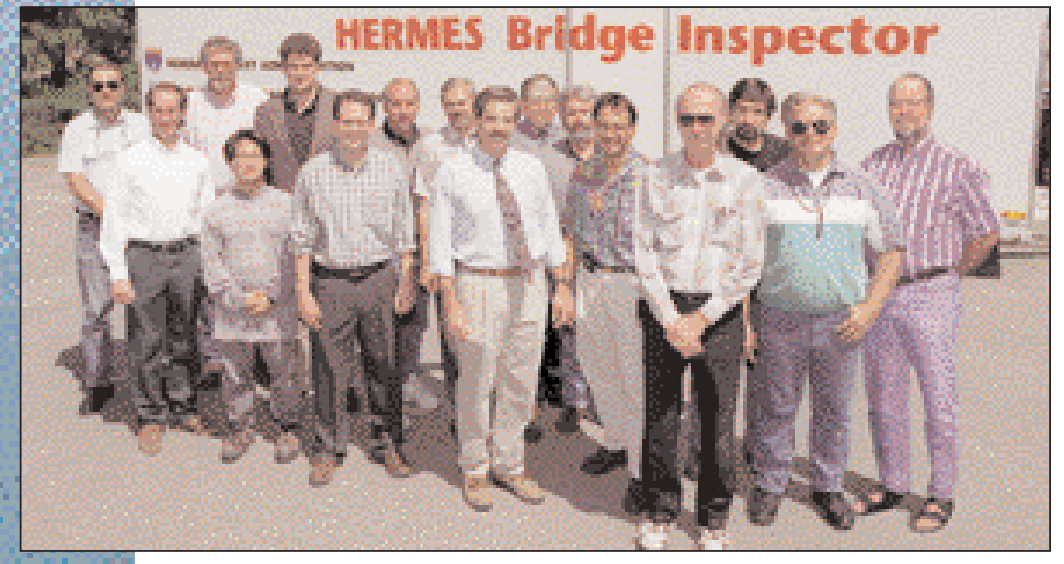

HERMES team members (left to right, front row) Scott Nelson, Ming Liu, Jeff Mast, Stephen Azevedo, Jose E. Hernandez, Bob Stever, and Richard Gilliam; (back row) Tom Story, Mark Vigars, Tom Rosenbury, Greg Dallum, Holger Jones, Pat Welsh, George Governo, and John Warhus. inspecting the concrete beds of rapid transit systems, examining the interior area of highway overpasses, and inspecting the walls and roofs of transportation tunnels. With HERMES, bridge inspectors can drive over a bridge at highway speeds and obtain diagnostic radar views of the subsurface structure without having to close the bridge or remove the asphalt overlay. The Federal Highway Administration estimates that HERMES will save the government about $\$ 100$ million per year on bridge deck repairs and rehabilitation.

Lloyd Hackel, C. Brent Dane, Steven Telford, James Wintemute, William Manning, and Balbir Bhachu along with James Daly and James Harrison of New Jersey-based Metal Improvement Co. Inc. shared an award for developing a laser-peening system that instills deep compressive stress into metals, which is expected to extend their lifetime three- to five-fold over conventional treatments. This high-energy, high-average-power laser permits the introduction of this important metal surface treatment process on an industrial scale for the first time. 


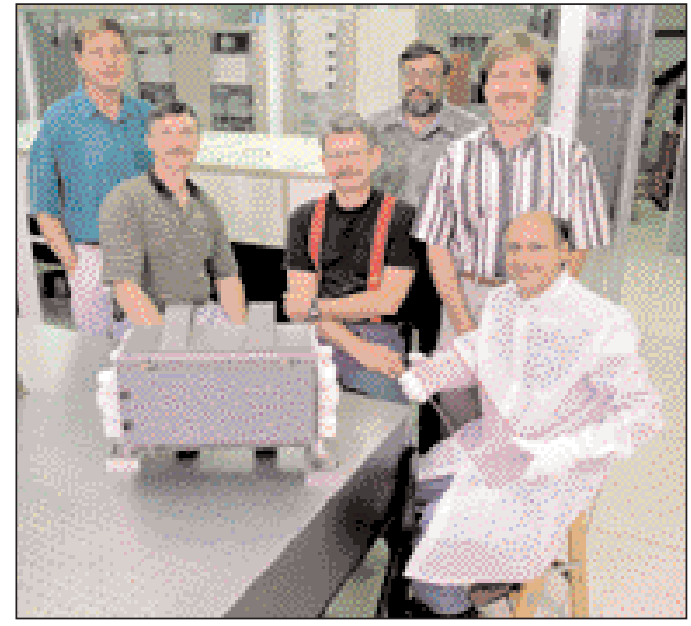

Laser peening system developers (left to right) Lloyd Hackel, Bill Manning, Jim Wintemute, Steve Telford, Brent Dane, and Balbir Bhachu.
The major applications of laser peening will be to treat metal components such as aircraft fan blades, disks, and rotors; helicopter drive gears and power train systems; hip replacement joints in the medical industry; and oil drilling collars and mud pumps to increase resistance to fatigue and stress corrosion.
Bill Colston Jr., Matthew Everett, Luiz Da Silva, Jim Cox, and Ken Haney from the Medical Technology Program, sponsored by the Engineering, Lasers, and Defense and Nuclear Technologies directorates, along with Linda Otis of the University of Connecticut Health Center, shared an award for a new optical dental imaging system that can diagnose periodontal disease and detect cavities. The system noninvasively images internal tooth and soft tissue microstructure for dental applications. It consists of a handheld scanner that produces high-resolution, cross-sectional images of all dental tissues.

Applications for this new system include diagnosis of periodontal diseases, detection of cavities, and evaluation of dental restorations. It allows safe, painless imaging to take the place of mechanical probing and radiographic imaging, permits ultrahigh-resolution with 10-micrometer resolution, and provides accurate imaging of all dental tissue.

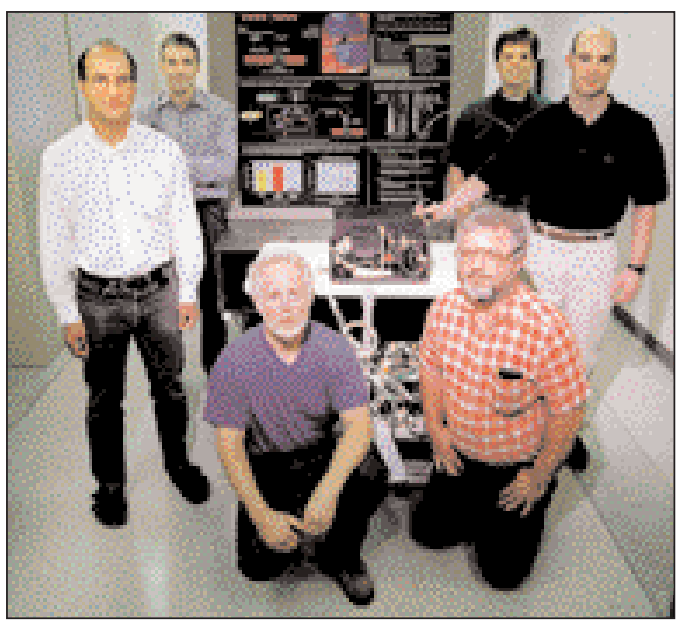

Two-color fiber-optic infrared temperature system developers (kneeling, left to right) James Cox and Kenneth Haney, (standing) Peter M. Celliers, Luiz Da Silva, Duncan Maitland, and Ward Small (see next page).

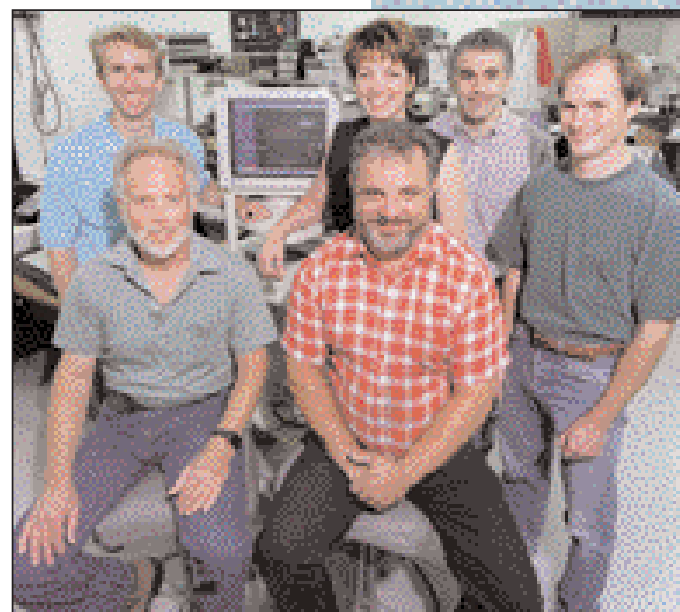

Optical dental imaging developers (left to right, front row) Jim Cox, Ken Haney; (back row) Bill Colston, Linda Otis, Luiz Da Silva, and Matt Everett.

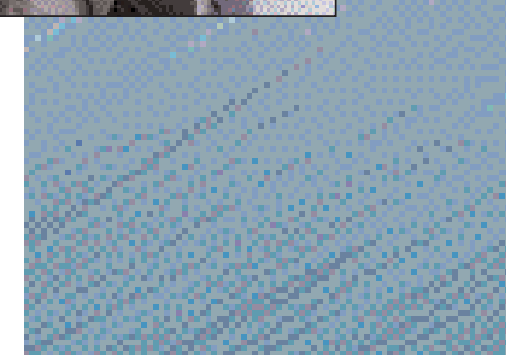


Wa rd Small IV, Peter Celliers, Duncan Maitland, James Cox, Ken Haney, and Luiz Da Silva shared an award for a two-color fiber-optic infrared temperature system. This sensor measures temperature and emissivity for noninvasive medical and industrial applications. The process is fast, accurate, and features high-spatial resolution and maneuverability, a variable working distance, and low-temperature sensitivity.

The main applications for this sensor include temperature-controlled laser delivery for tissue welding in a broad range of surgical applications, including grafts, skin wound closure, urethral closure, and nonsurgical applications in nerve repair; laser-based minimally invasive surgery; and monitoring the surface temperature of silicon wafers during the dry-etching process for semiconductor processing.

John S. Taylor along with Mark Piscotty and Ken Blaedel of Engineering shared an award for the OptiPro Acoustic Emission Detector Grinding Wheel Proximity Sensor. This sensor is a real-time feedback product used to substantially improve the

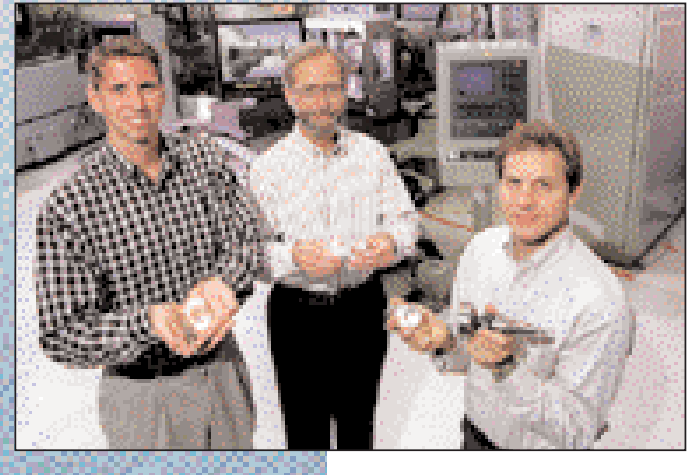

OptiPro Acoustic Emission Detector developers Mark Piscotty, Johns. Taylor, and Kenneth efficiency of precision optics manufacturing. The technology senses the precontact separation between fine abrasive grinding tools and optical glass parts during the grinding operation, even in such hostile environments as swirling coolant, rotating spindles, and background machine noise, enabling the tool to speed toward the lens without risk of crashing into the fragile lens surface.

Applications include the grinding of precision spherical optics; fine grinding of other brittle materials, such as ceramics; gauging of grinding wheel shape and position; and fabrication of precision aspheric optics. The process will significantly improve the productivity of computer-controlled lens grinding and help provide the economic justification for companies moving from manual to automated production platforms.

\section{Fellowships}

\section{American Physical Society (APS)}

Luiz Da Silva, acting Associate Program Leader for the Medical Technology Program, was elected a fellow of the American Physical Society for his outstanding contribution to physics. Da Silva was cited for "his pioneering use of x-ray lasers and lasergenerated shock waves to the study of high-density plasmas." This award brings the total number of APS fellowships earned by the ICF Program since 1976 to 46. The APS selects only one percent of its total membership for fellowship each year.

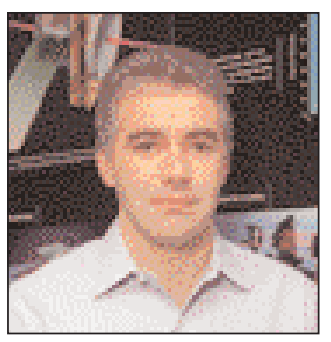

Da Silva's work extends the study of high-density plasmas to conditions relevant to planetary science, astrophysics, and inertial confinement fusion for both energy and nuclear weapons Stockpile Stewardship research. Da Silva earned his Ph.D. in physics from the University of British Columbia. The Danville resident joined the Lab in 1989.

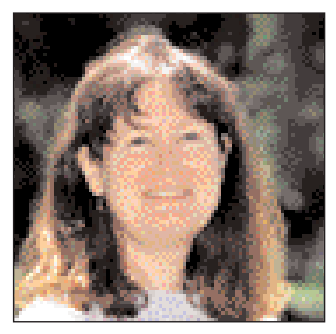

Gail Glendinning, an ICF Program employee, was named an APS fellow in 1998 as well for her "clear and illuminating experimental investigations of ablation-front Rayleigh-Taylor instability, laser imprinting, and nonlinear hydrodynamic instabilities relevant to inertial confinement fusion, high-energy-density physics, and astrophysics." A Fremont resident, Glendinning received her Ph.D. in experimental nuclear physics from Duke University and joined the Laboratory in 1985. 
Guy Dimonte, also an ICF Program employee, was named an APS fellow for his "outstanding contributions to understanding turbulence and mixing in high-energy-density fluids by novel experimental techniques and facilities." Dimonte developed new target configurations for the Nova laser and a Linear Electric Motor that can accelerate projectiles up to 1000 g's to investigate fluid turbulence and mixing. His experimental results have application in areas of study as diverse as volcanic islands, under-

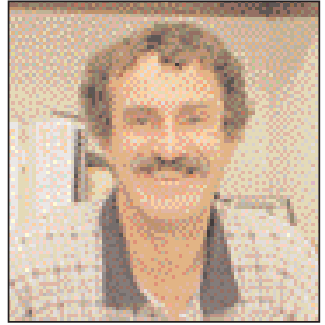
ground salt domes, astrophysics, and inertial confinement fusion for both energy and nuclear weapons Stockpile Stewardship research. Dimonte received his Ph.D. from the University of California at San Diego. A San Ramon resident, Dimonte joined the Laboratory in 1988.

\section{Institute of Electrical and Electronics-Engineers (IEEE)}

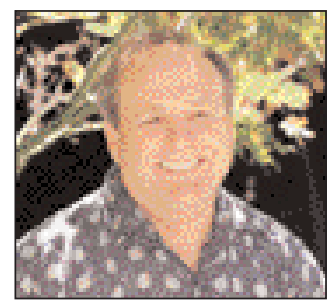

James Candy, who is director of the Center for Advanced Signal and Imaging Sciences and a staff scientist in Engineering matrixed to Lasers, was named an IEEE fellow for his contributions to model-based ocean acoustic signal processing. A resident of Danville, he has been at the Lab since 1976. Candy earned his bachelor's degree at the University of Cincinnati and his master's and Ph.D. degrees from the University of Florida.

\section{Other Awards}

\section{Weapons Recognition of Excellence Awards}

Each year the DOE recognizes dedicated people who have made outstanding contributions to the nation's nuclear weapons program. The 1998 Laser Programs award recipients were:

Members of the A Program Nova Experiments Team:

Joe Bauer, Defense and Nuclear Technologies-A Division (A); Kim Budil, (ICF); Tina Back (ICF); Jeff Koch (ICF); Bob Cauble, Physics \& Space Technology (P\&ST)—V Division (V); Anthony Demiris, Mechanical Engineering (ME); David Farley (A); Dennis Johnson (ME); Larry Logory, Nonproliferation, Arms Control, and International Security-Z Division; Hedley Louis (ME); Mike McClure (ME); Paul Miller (A); Ted Perry (A); Tom Peyser (A); Phil Ramsey (ME); Jack Reynolds (ME); Don Smith (A); Peter Stry (A); Alan Wan (A); Richard Ward (A); Stephen Murray (A); Juan Moreno (A); and Joe Nilsen (A) for demonstrating the usefulness of high-intensity lasers to the nuclear weapons program. Through their experimental design and execution work, they showed that important radiation hydrodynamic issues in weapons physics can be addressed using large lasers through the use of proper scaling relationships,

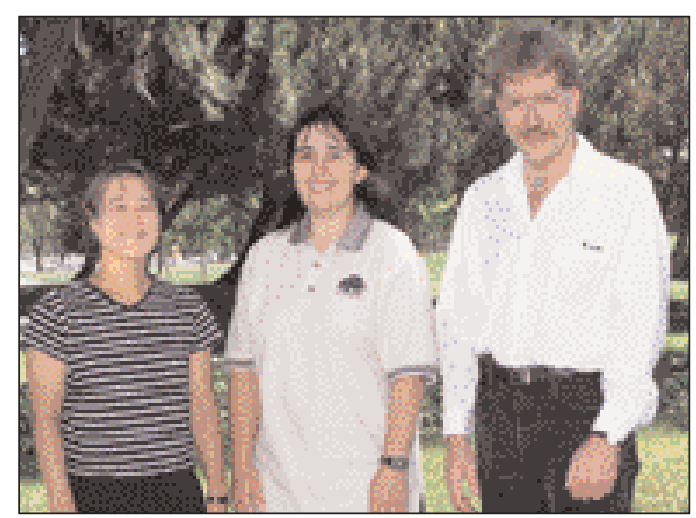

Members of the Nova Experiment team (left to right) Tina Back, Kim Budil and Jeff Koch. 
innovative target design, and new diagnostic techniques. This work broke new ground in the fabrication of small-scale weapons physics targets and made it possible to perform high-quality experiments in a regime severely limited by the energy density available from even the most powerful lasers.

Members of the Deuterium Equation of State (EOS) Team:

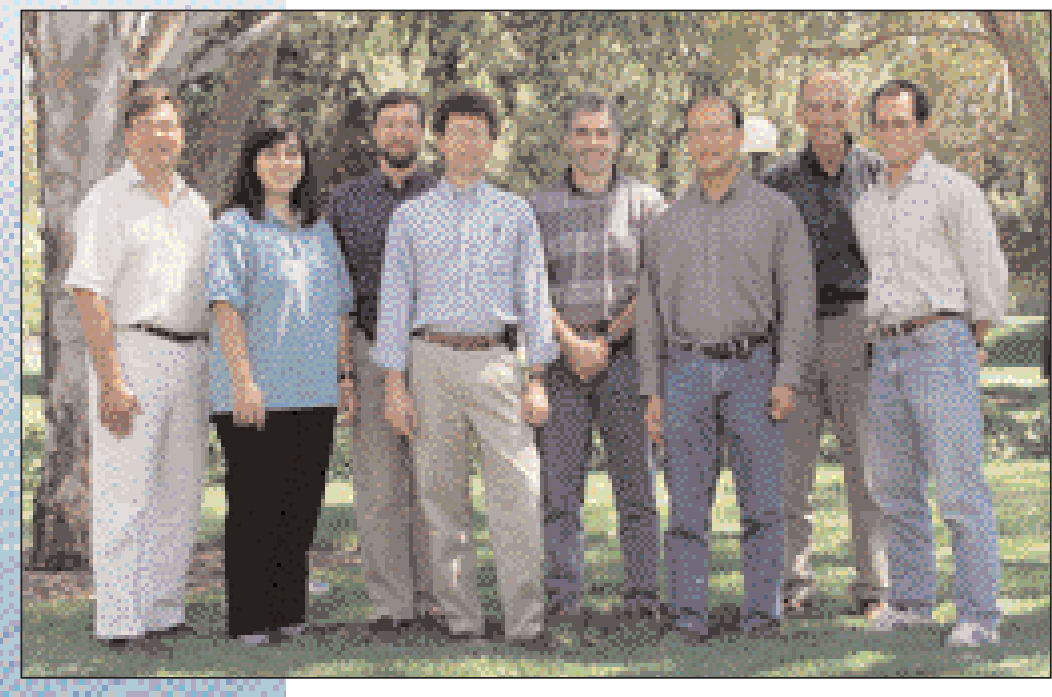

Steve Weber, Kim Budil, David Gold, Bob Cauble, Luiz Da Silva, Peter Celliers, Marvin Ross, and Gilbert Collins
Kim Budil (ICF) Bob Cauble (V); Peter Celliers (ICF); G. W. "Rip" Collins (ICF); Luiz Da Silva (ICF); Mark Foord (V); David Gold (ICF); Marvin Ross (P\&ST); and Steve Weber (X Division) for making the innovative use of Nova technology with advanced diagnostics to measure the EOS of deuterium at high-pressure dissociation and ionization of $\mathrm{D}_{2}$. New calculations of hydrodynamic phenomena using these results in modified EOS models have shown improved agreement with historical data, resulting in significant improvements in the understanding of a variety of experiments.

\section{Federal Laboratory Consortium (FLC) Award}

The FLC Annual Awards for Excellence in Technology Transfer recognize Laboratory employees who have accomplished outstanding work in the process of transferring laboratory-developed technology to the private sector. The Laboratory is limited to a maximum of four submissions per year based on the number of its employees. Nominations are made by the Laboratory representative and are judged by representatives from industry, state and local governments, academia, and the laboratories. The nominations alone represent a high honor among peers and laboratory management. Thirty awards are presented each year.

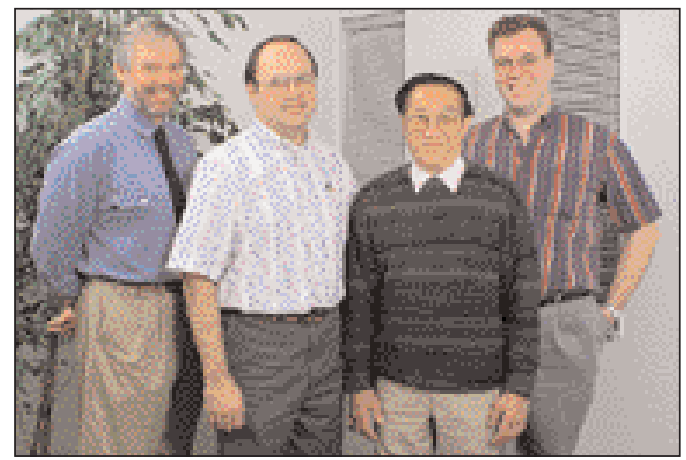

FLC Award winners (from left to right) Stephen Vernon, Richard Levesque, Swie-In Tan, and Patrick Kearney.
Stephen Vernon, Don Kania, Patrick Kearney, Swie-In Tan, and Richard Levesque of the Advanced Microtechnology Program received an FLC Award for their submittal: "UltraClean Ion Beam Sputter Deposition System (IBD-350)." 
Peter Celliers, Luiz Da Silva, and Dennis Matthews of the Laser Programs along with Richard London and Duncan Maitland of Defense and Nuclear Technologies; William Benett, Peter Krulevitch, and Abraham Lee of Engineering; and Patrick Fitch of the Biology and Biotechnology Research Program were selected to receive an FLC Award for their submittal: "A Stroke Treatment System to Emulsify Blood-Clots and Quickly Restore Blood Flow Following a Stroke, Based on Fiber-Optic-Delivered, Opto-Acoustic Thrombolysis."

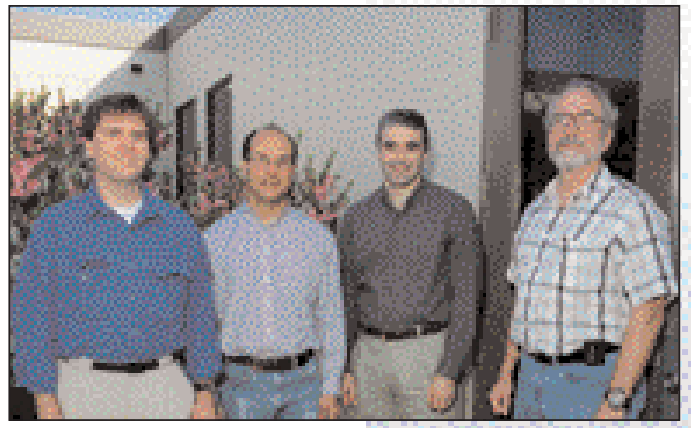

FLC award winners (from left to righf) Duncan Maitland, Peter Celliers, Luiz Da Silva; and Dennis Matthews.

\section{Special Recognitions}

John Holzrichter and John Trenholme were among the authors honored as part of the Naval Research Laboratory's 75th anniversary celebration. The laboratory honored the 75 "most important papers" published since its founding. Holzrichter and Trenholme were co-authors of "A Glass Disk Laser Amplifier."

Electronics engineer Steve Azevedo was selected as one of 83 prominent young engineers to take part in the National Academy of Engineering's "Frontiers of Engineering" symposium in September 1998. The participants, from industry, universities, and government laboratories, were chosen from more than 240 candidates nominated by other engineers or institutions. Azevedo is the Laser Programs project leader for the micropower impulse radar technology.

\section{Excellence in Fusion Energy Award}

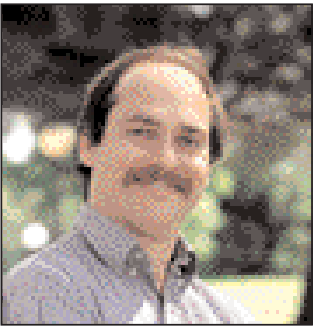
glass, and near-sonic gas coolant.

\section{APS Award for Excellence in Plasma Pbysics Research}

Gilbert Collins, Luiz Da Silva, and Peter Celliers, along with Robert Cauble of the Physics and Space Technology Directorate, shared an APS Award for Excellence in Plasma Physics Research in 1998. The four were commended for "an exquisite series of experiments, using the Laboratory's Nova laser, to measure 


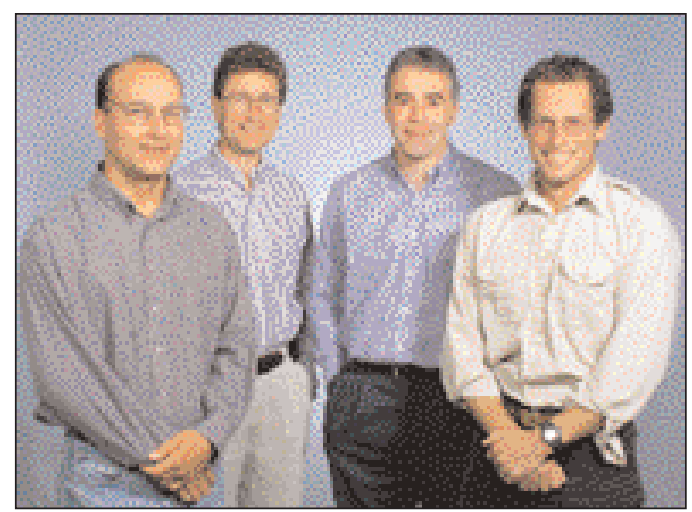

APS Plasma Physics Award winners (left to right) Peter Celliers, Robert Cauble, Luiz Da Silva, and Gilbert Collins. the high-pressure properties of hydrogen across the molecular insulator to monatomic metal transition." The results of this work are directly relevant to theories of the atmospheres of giant planets and low-mass stars and to the design of miniature fuel targets for inertial confinement fusion research.

\section{Society for Tecbnical Communications Awards}

The Society for Technical Communications (STC), the largest organization of its type, is dedicated to advancing the arts and sciences of technical communication. Its 20,000 members include technical writers, editors, graphic designers, videographers, multimedia artists, and others whose work involves making technical information available to those who need it. The mission of the society is to improve the quality and effectiveness of technical communication for audiences worldwide.

There are four levels of awards: distinguished, excellence, merit, and achievement. Four technical documents and four technical art pieces from the Laser Programs won STC awards in 1998.

Jason Carpenter, editor; Al Miguel, editor; Pam Davis, artist/compositor; Clayton Dahlen, artist; Sandy Lynn, artist; Mark McDaniel, artist; Robert Kirvel, (Technical Information Department [TID]) editor; Cindy Cassady, editor; Dabbie Schleich, editor; Don Correll, managing editor; Roy Johnson, classification editor, and William Kruer, scientific editor, shared an Award of Merit for the Inertial Confinement Fusion Quarterly Report, January-March 1997, entered in the Scientific and Technical Reports category.

Jason Carpenter, editor; Al Miguel, editor; Pam Davis, artist/compositor; Ken Ball, (Whyte Ball) artist; Sandy Lynn, artist; Cindy Cassady, editor; Ann Parker, (TID) editor; Clayton Dahlen, artist; Mark McDaniel, artist; Don Correll, managing editor; Roy Johnson, classification editor, and John Murray, scientific editor, shared an Award of Merit for the Inertial Confinement Fusion Quarterly Report, April-June 1997, also entered in the Scientific and Technical Reports category.

Jason Carpenter, editor; Al Miguel, editor; Pam Davis, artist/compositor; Ken Ball, (Whyte Ball) artist; Clayton Dahlen, artist; Sandy Lynn, artist; Mark McDaniel, artist; Janet Orloff, artist; Galen Hazelhofer, (TID) artist; Robert Kirvel, (TID) editor; Cindy Cassady, editor; Joy Perez, editor; Dabbie Schleich, editor; Ann Parker, (TID) editor; Cara Corey, (TID) editor; Karen Lew, (TID) editor; James Hammer, X Division; William Kruer, X Division; John Murray, ICF Program; Don Correll, managing editor; Roy Johnson, classification editor, and Charles Vann, scientific editor, shared an Award of Achievement for the ICF Annual Report, 1997, entered in the Scientific and Technical Reports category. 


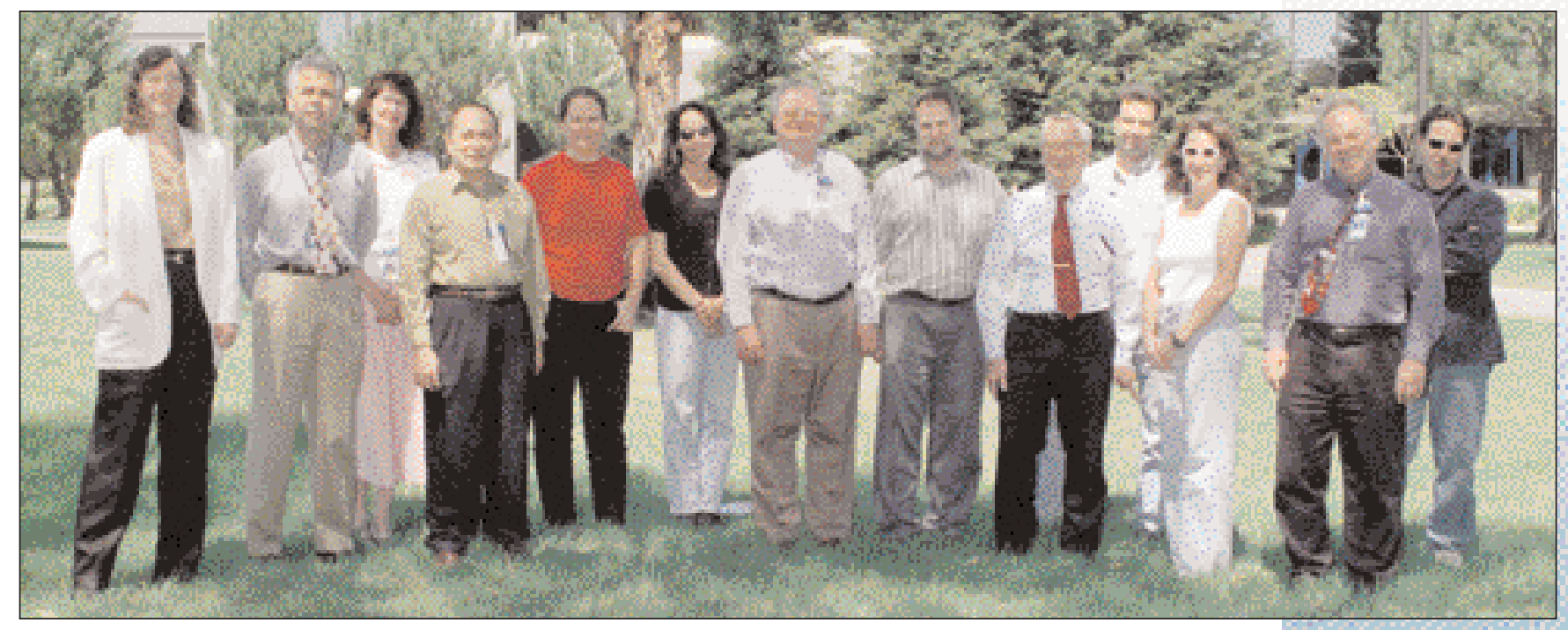

STC Award winners (left to right) Ann Parker, Don Correll, Cindy Cassady, Al Miguel, Sandy Lynn, Janet Orloff, John Murray, Clayton Dahlen, Roy Johnson, Jason Carpenter, Pam Davis, William Kruer, and Mark McDaniel.

Cindy Cassady, editor; John Hunt, scientific editor; and Jo Dee Beck, Administrator, shared an Award of Achievement for the NIF Laser System Performance Ratings, entered in the Scientific and Technical Reports category.

In the STC Technical Art competition, two entries won Awards of Excellence-the 1997 Laser Highlights Brochure designed by artist Sandy Lynn and the "Laser Tune-Up" photo produced by photographer Bryan Quintard.

Two entries also won Awards of Merit in the Technical Art competition-the "Gradient Reflections" photo by Bryan Quintard and the "Mammoth Discovery" photo, also by Bryan Quintard.

\section{LLNL Director's Performance Award}

In 1998, the following Laser Programs personnel received Director's Performance Awards:

Members of the Beamlet Engineering and Operations Team matrixed to the Laser Programs, including: William Behrendt, Electronics Engineering (EE); Gene Frieders (EE); Thomas McWilliams, Mechanical Engineering (ME); Norman Nielsen (ME); Guy Robitaille (ME); Terry Schwinn (ME); Timothy Weiland (EE); and Michael Werve (ME) were recognized for their major contributions towards the successful decommissioning of the Beamlet Laser. The Beamlet Laser, decommissioned at the end of July, has made a tremendous impact on the NIF laser design, from the fiber oscillator system to the final focus in the system. From the first Beamlet activation in 1994 to the present, it has validated or changed laser component design, propagation design, optics specifications, and most recently, final optics design.

Members of the High-Average-Power Visible Solid-State Lasers Team including: Isaac Bass (EE); Jim Chang, (LP); Curt Cochran (ME); Ernest Dragon (ME); Chris Ebbers (LP); Gaylen Ebert (ME); Glen Huete (ME); Keith Kanz (ME); 
and Angela Niles (ME) received the award for their exceptional commitment in time and teamwork toward developing world-record performance solid-state laser technology that has displaced the use of copper vapor lasers as the pump lasers for AVLIS, thereby reducing plant capital construction costs by $10 \%$. Over a twoyear period, this team has been able to more than double the average output power and efficiency of visible solid-state lasers for use in AVLIS and materials processing. This work has led to two very successful solid-state laser options-one lamp pumped and the other diode-laser pumped.

\section{In Memoriam-Carl Haussmann}

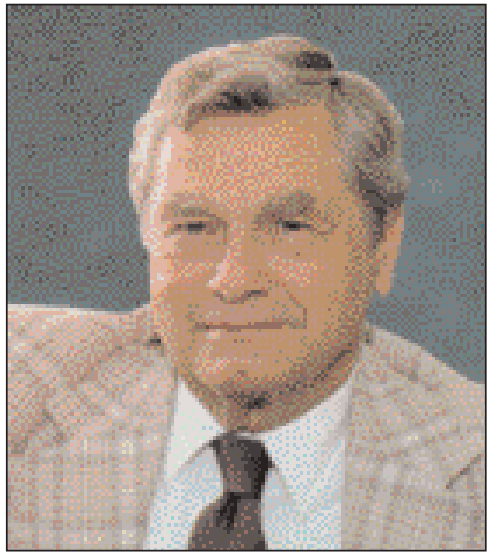

Carl Haussmann, the first Associate Director (AD) of the newly founded Laser Programs in 1972, a relentless advocate for increased federal funding for laser research, and the instrumental force in beautification of the Laboratory site, passed away in July 1998. Haussmann made an indelible mark on the Laser Programs and the Laboratory throughout his distinguished career.

Born in Geneva, N.Y., on August 26, 1924, Haussmann attended the U.S. Military Academy at West Point, where he graduated in 1946 with a bachelor's degree in military art and engineering. He also earned a master's degree in physics at Pennsylvania State University in 1951.

Haussmann came to the Laboratory in 1953 as an Army officer to work on nuclear weapons design and joined the Laboratory as a civilian in 1955. In the early 1970s, as AD for Plans and Lasers, he pulled together all of the Lab's laser research efforts into one focused program. He recruited expertise from outside the Lab and worked tirelessly for federal funds to build the Laser Programs. Haussmann focused the Program's efforts toward laser fusion and its potential utility, laser science, thermonuclear explosion physics, diagnostic and code development, effects simulators, and civil power. 


\section{Laser Programs' Striving for Excellence}

This excellence is measured, in part, by the following metrics for the past four years.

\begin{tabular}{|c|c|c|c|c|}
\hline Category & 1995 & 1996 & 1997 & 1998 \\
\hline $\begin{array}{l}\text { Major Awards } \\
\text { E.O. Lawrence, Edward Teller, Simon Ramo } \\
\text { Fusion Power Assoc's., APS, OSA, IEEE, ANS, } \\
\text { Federal Laboratory Consortium }\end{array}$ & 7 & 6 & 6 & 4 \\
\hline R\&D 100 Awards & 3 & 5 & 4 & 5 \\
\hline Society Fellowships & 2 & 8 & 3 & 5 \\
\hline Patent Disclosures & 35 & 71 & 62 & 52 \\
\hline Patent Applications & 34 & 26 & 18 & 35 \\
\hline Patents Issued & 29 & 33 & 17 & 27 \\
\hline Executed Licenses & 9 & 12 & 9 & 5 \\
\hline Licensing Income & $\$ 875 K$ & \$927K & $\$ 1,222 \mathrm{~K}$ & $\$ 921 \mathrm{~K}$ \\
\hline Refereed Publications & 151 & 132 & 123 & 109 \\
\hline U.C. Science \& Technology Assessment & "Outstanding"* & "Outstanding"* & "Outstanding"* & "Outstanding"* \\
\hline $\begin{array}{l}\text { DOE Assessment of ICF Program } \\
\text { *highest rating }\end{array}$ & "Outstanding"* & "Outstanding"* & "Outstanding" * & "Outstanding" * \\
\hline
\end{tabular}



(x)

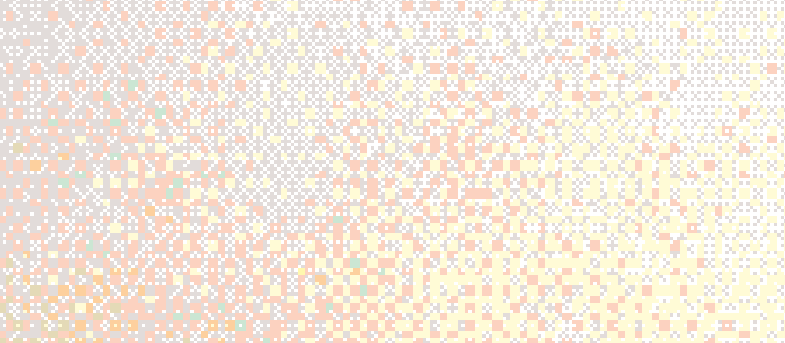

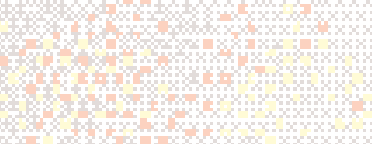

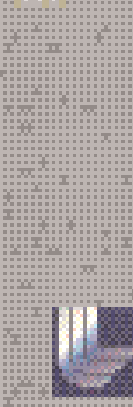

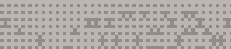

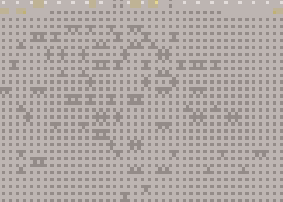

$(x+2)$
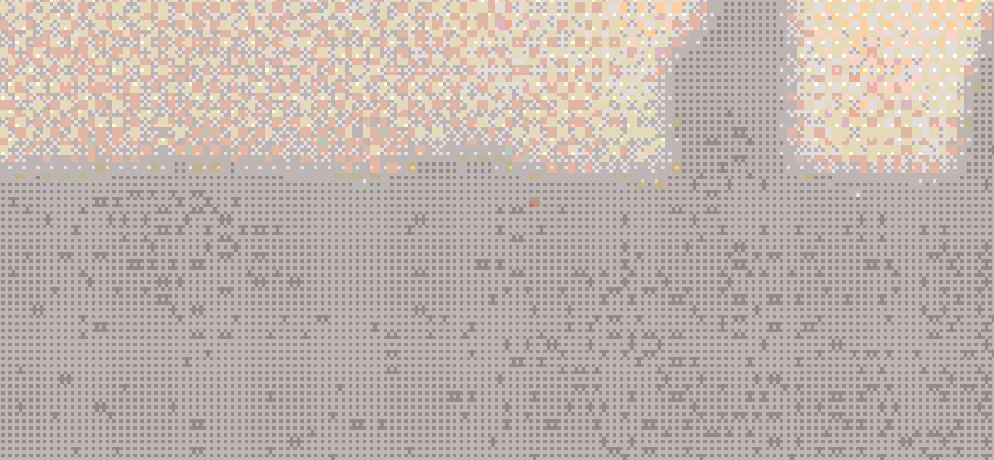

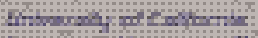

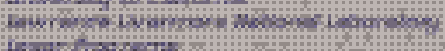

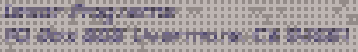

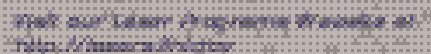

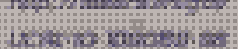
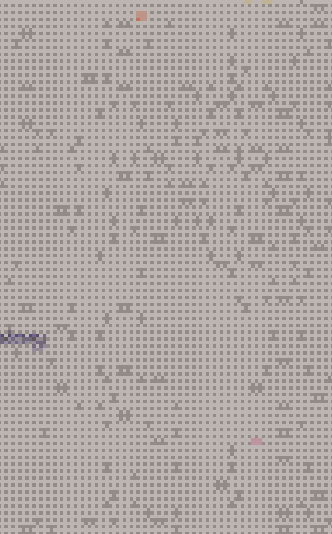